\title{
Como o grau de desigualdade afeta a propensão marginal a consumir? Distribuição de renda e consumo das famílias no Brasil a partir dos dados das POF 2002-2003 e 2008-2009 *
}

\section{Fabrício Pitombo Leite ${ }^{* *}$}

\begin{abstract}
Resumo
$\mathrm{O}$ artigo visa investigar a relação entre mudanças na distribuição de renda e seus impactos na propensão marginal a consumir para a economia como um todo. Para tal, utiliza os dados das duas últimas pesquisas de orçamentos familiares (POF) realizadas no Brasil, 2002-2003 e 2008-2009, tomando a renda familiar total e calculando uma variável de despesa familiar total para as duas pesquisas. São apresentados os índices de Gini para a renda familiar total e estimativas, por meio dos microdados e dos centésimos da população, para a propensão marginal a consumir agregada. É efetuado ainda o ajuste de poligonais no intuito de captar diferenças entre as propensões marginais a consumir de dois grandes grupos de renda e procede-se a manipulações contrafactuais na busca pela mensuração do impacto de efeitos redistributivos livre de outras influências sobre a propensão marginal a consumir agregada.
\end{abstract}

Palavras-chave: Distribuição de renda; Desigualdade; Consumo; Propensão marginal a consumir; Pesquisa de Orçamentos Familiares.

\begin{abstract}
How does the degree of inequality affect the marginal propensity to consume? Income distribution and family consumption in Brazil based on 2002-2003 and 2008-2009 HBS data

The paper intends to analyze the relationship between changes in income distribution and the impacts of these changes on the marginal propensity to consume for the economy as a whole. Data from the last two household budget surveys (HBS) realized in Brazil (2002-2003 and 2008-2009) are utilised, by taking the total household income and computing a total household expenditure variable for the two surveys. The Gini indexes for total household income and estimates for the aggregate marginal propensity to consume are presented, via microdata and hundredths of the population. In addition, polygonals are adjusted with the intention of capturing the differences between the marginal propensities to consume of two major groups of income. Some counter-factual manipulations are made to measure the impact of redistributive effects free other influences on the aggregate marginal propensity to consume.
\end{abstract}

Keywords: Income distribution; Inequality; Consumption; Marginal propensity to consume; Household budget survey.

JEL C81, D31, E21.

De um lado, a acentuada queda da desigualdade na distribuição de renda para o Brasil, nos últimos anos, já caracteriza um fato bem documentado (e.g. Barros et al., 2006; Hoffmann, 2006; Hoffmann; Ney, 2008; Hoffmann, 2010a) e dispensa

\footnotetext{
* Artigo recebido em 25 de janeiro de 2014 e aprovado em 8 de agosto de 2015.

** Professor da Universidade Federal do Rio Grande do Norte (UFRN), Natal, RN, Brasil. E-mail: fabriciopleite@ufrnet.br.
} 
maiores apresentações. De outro lado, mesmo a conexão teórica entre mudanças na distribuição de renda e alterações da propensão marginal a consumir (e, por conseguinte, do multiplicador) carece de sedimentação na literatura macroeconômica, e quando há menções ao caso brasileiro recente (e.g. Carneiro, 2011) ${ }^{1}$, as afirmações não são acompanhadas do mesmo escrutínio estatístico efetuado pelos estudiosos da distribuição de renda.

Este trabalho tem o duplo propósito de esclarecer qual a conexão existente entre distribuição de renda e propensão marginal a consumir, o que explica, em outros termos, como alterações na distribuição de renda podem impactar no próprio nível de renda e fazer uma análise pormenorizada dos dados relativos às duas últimas pesquisas de orçamentos familiares (POF), como em Hoffmann (2010a, 2010b), mas com o foco voltado às implicações macroeconômicas da análise.

Se é ponto pacífico que a desigualdade da distribuição de renda apresentou queda substancial recentemente, os anos de realização das últimas POF, 2002-2003 e 2008-2009, oferecem aos economistas a rara oportunidade de observar um "experimento controlado" típico, com os objetivos da pesquisa se alinhado perfeitamente a um estudo empírico acerca do consumo para o Brasil. Diferentemente de trabalhos recentes para o Brasil (Gomes, 2004; 2010; 2012; 2013; Reis et al., 1998; Schettini et al., 2012), que estimam funções consumo a partir de dados de séries temporais, contudo, as pesquisas de orçamento nos possibilitam estimativas por meio de dados de corte com tamanhos de amostra bastante elevados.

Na primeira seção faremos uma breve recuperação de debate travado acerca da influência da distribuição de renda na propensão marginal a consumir, ocorrido após o lançamento da Teoria Geral e contando com uma pequena intervenção de Keynes, fazendo ainda menções pontuais a contribuições mais recentes. $\mathrm{Na}$ seção seguinte, caracterizaremos preliminarmente os dados utilizados das POF 2002-2003 e 2008-2009 para, na terceira seção, procedermos às primeiras estimativas da propensão marginal a consumir apresentadas neste estudo ${ }^{2}$. Posteriormente, partiremos para o ajuste de poligonais aos dados, no intuito de procurar por diferenças entre as propensões marginais a consumir em diferentes grupos de renda. Após a repartição em dois grandes grupos de renda, iniciaremos uma série de manipulações contrafactuais acerca da influência estrita da redistribuição de renda sobre a propensão marginal a consumir agregada, passando ainda por uma quinta seção que visa decompor o índice de Gini de modo a questionar o principal determinante da queda no mesmo: se a queda da desigualdade entre os grupos de

(1) "O aumento do consumo decorrente da melhora da distribuição da renda, com o concomitante aumento do multiplicador, tem ainda potencial significativo, embora decrescente" (Carneiro, 2011, p. 22-23).

(2) A manipulação dos microdados, inclusive estimativas a partir dos mesmos, foi realizada utilizando o SPSS 17.0; estimativas posteriores a partir dos centésimos e a representação gráfica de alguns resultados foram realizadas no Eviews 4.1; o Gráfico 3 foi obtido utilizando o Mathematica 5.1. 
renda ou dentro de cada grupo. As seções seguintes, a partir dos décimos (seção 6) e dos centésimos ( seção 7) da população, ilustram como a queda da desigualdade afeta a propensão marginal a consumir agregada, fazendo uma aproximação gradativa com a realidade e mostrando a magnitude desses efeitos redistributivos por meio de contrafactuais. Nas considerações finais, ilações mais genéricas acerca do que não foi explorado no artigo e potenciais impactos sobre o nível de renda são considerados.

\section{Uma breve recuperação do debate pós Teoria Geral}

A influência que mudanças na distribuição de renda podem exercer sobre a propensão marginal a consumir é objeto de controvérsia desde o advento do conceito, com o foco do debate variando da simples exegese em torno da Teoria Geral a ilustrações estatísticas de que diferentes categorias de rendimento (classes selecionadas ou estratos) têm comportamentos diferentes com relação ao consumo ou de que há correlação entre uma medida de desigualdade e a propensão marginal a consumir. Comumente, essas duas vertentes confluem para a ideia de que uma ênfase maior deveria ter sido dada por Keynes (1936), preferivelmente elegendo explicitamente outra variável explicativa em sua função consumo.

Nosso objetivo ao longo deste trabalho é buscar a conexão entre distribuição de renda e propensão marginal a consumir, e não entre consumo e outra variável representativa da distribuição de renda, e esse foi o caminho seguido, por exemplo, por Stone e Stone (1938), que na esteira do lançamento da Teoria Geral procedem a estimativas da propensão marginal a consumir de diferentes maneiras, iniciando por dados de orçamentos familiares (Ibid, p. 2-10), sem descuidar do fato de que a distribuição de renda afeta a própria propensão marginal a consumir (Ibid, p. 7).

Gilboy (1938) dedica uma seção de seu artigo (Ibid, p. 121-123) para discutir a distribuição de renda, reconhecendo que Keynes "estava ciente, é claro, que a distribuição de renda pode mudar e pode causar mudanças na propensão a consumir", apesar de relegar mudanças na distribuição para além do curto prazo, como destacado pela autora. Em uma hipotética redistribuição da renda, tornando-a mais igualmente distribuída, Gilboy (1938, p. 122) coloca em dúvida a possibilidade de um incremento na renda continuar gerando aumentos na poupança; ou seja, o que está em jogo é uma propensão marginal a consumir unitária tão logo a renda estivesse mais bem distribuída. A autora atribui, assim, o funcionamento da "lei psicológica fundamental" de Keynes ao tipo de sociedade em que vivíamos (vivemos), em decorrência de uma "distribuição de renda altamente assimétrica" (Gilboy, 1939, p. 637). Desse modo, considera que "não é impossível imaginar uma situação na qual os gastos de consumo poderiam aumentar absolutamente tanto quanto a renda ou, por um período curto de tempo, mais que a renda" (Ibid, p. 636). Keynes contra- 
$\operatorname{argumenta}^{3}$ a partir da ideia de que "se a lei psicológica não é satisfeita, então nós temos uma condição de completa instabilidade" (Gilboy, 1939, p. 634, grifos no original), como posteriormente se tornou conhecimento-padrão a partir da imagem de duas retas que não se cruzam no diagrama da "cruz keynesiana":

Se, quando a renda aumenta, os gastos aumentam em mais do que o aumento integral da renda, não há ponto de equilíbrio. Ou, no caso limite, em que os gastos aumentam exatamente em 100 porcento de qualquer aumento da renda, então nós temos um equilíbrio neutro, sem nenhuma preferência particular de uma posição sobre a outra. Nenhuma dessas condições parece ser característica do verdadeiro estado das coisas, exceto talvez por breves períodos quando as pessoas estão se acostumando a uma mudança que elas não previram” (Ibid).

Adicionalmente, Gilboy (1938) questiona a ideia de que mudanças na distribuição de renda são lentas o bastante para que as consideremos "seculares"; em oposição, pretende argumentar que mudanças nas mesmas são cíclicas, com a concentração de renda aumentando na fase de subida do ciclo. E reitera (Gilboy, 1939, p. 636) seu "ceticismo no que concerne à estabilidade de curto prazo desses fatores, [elencados em Keynes, 1936, p. 110] particularmente a distribuição de renda", deixando o mérito da questão para ser decidido por verificações empíricas ulteriores ${ }^{4}$.

Um dos estudos em que essa autora se baseia para advogar pelas variações cíclicas na distribuição de renda é o publicado por Staehle (1937), tendo sido este autor, em artigo subsequente que dava continuidade ao assunto (Staehle, 1938), objeto de uma pequena réplica de Keynes (1939), seguida da tréplica (Staehle, 1939). No que concerne à Teoria Geral, Staehle (1938, p. 138) acusa Keynes de ter "negligenciado as variações na distribuição de renda ao definir sua função da 'propensão a consumir'”.

A essa acusação, Keynes (1939) simplesmente respondeu que dificilmente poderia ter sido mais preciso ou enfático ao considerar este fator na Teoria Geral, citando diretamente o trecho que introduz o conceito de propensão a consumir (Keynes, 1936, p. 90-91), e ainda enumerando alguns outros (Ibid, p. 92, 121, 262).

(3) Em carta-resposta pessoal endereçada a Gilboy e reproduzida com permissão nesse artigo (Gilboy, 1939). Alguns posicionamentos de Keynes sobre outros pontos não são do nosso interesse imediato neste trabalho, de modo que não estamos reproduzindo o debate integralmente, mas somente o que se relaciona à distribuição de renda.

(4) Ao que nos consta, as medidas de desigualdade na distribuição de renda têm apontado, em geral, mudanças muito lentas, levando Barros, Henriques e Mendonça (2000) a classificarem a persistência do índice de Gini, no Brasil, no patamar de 0,60 por duas décadas (até 1998), como uma "inaceitável estabilidade da desigualdade de renda no Brasil" (Ibid, p. 136-137). Tal persistência anterior somente reforça o interesse do nosso estudo, dada a "evolução recente da desigualdade de renda no Brasil, a qual, a partir de 2001, começou a declinar de forma acentuada e contínua" (Barros et al., 2006, p. 107), nos ajudando a caracterizar o ocorrido entre os anos de realização das duas últimas POF como um "experimento controlado" à disposição dos economistas. 
O reconhecimento de Staehle (1939, p. 129) de que de fato "negligenciou completamente as referências à influência da distribuição de renda sobre a 'propensão a consumir' que estão contidas no livro do Sr. Keynes" vem acompanhado de considerações acerca da distribuição funcional de renda para classes selecionadas, e ainda acerca da relação desta com a distribuição pessoal (como é denominada hoje) de renda. Curiosamente, fica para Keynes o fardo de ter tratado somente de variações da distribuição entre classes selecionadas, em termos das parcelas da renda que são apropriadas pelas mesmas ${ }^{5}$.

Assim, teria ficado sem consideração a influência de mudanças na distribuição pessoal de renda, sem que houvesse alteração nas parcelas apropriadas pelas classes em questão. De acordo com Staehle (1937, p. 138, grifos no original), a propensão marginal a consumir da sociedade pode ser entendida como "uma média ponderada das propensões marginais dos indivíduos, na qual a ponderação precisa ser proporcional à parcela que a mudança em cada renda individual tem na mudança da renda total". Desse modo, esse autor parte para uma investigação estatística com dados para a Alemanha, buscando a relação entre uma proxy para a propensão média a consumir (vendas no varejo sobre a massa salarial) e uma medida de desigualdade, encontrando resultados que o levam a concluir que há alterações na desigualdade no curto prazo e essas alterações contribuem estatisticamente para uma explicação da propensão a consumir, resultados endossados por suas considerações posteriores (Staehle, 1938) $)^{6}$.

Deveria se explicitar, contudo, que tratar de uma redistribuição em favor de uma classe com uma menor propensão a consumir é uma maneira equivalente de falar de uma transferência regressiva (de quem ganha menos para quem ganha mais, aumentando, portanto, a desigualdade da distribuição pessoal de renda). Uma vez que as classes se diferenciem justamente por suas diferentes propensões a consumir (como em Kalecki ou nas teorias de crescimento e distribuição do tipo KaldorPasinetti), redistribuir em favor de uma classe com maior propensão a consumir é

(5) Curiosamente, se levarmos em conta que, modernamente e em alguns círculos, Keynes é frequentemente acusado de não ter tratado da distribuição funcional da renda, tendo sido esta uma grande contribuição restrita a Kalecki e incorporada aos modelos de crescimento e distribuição do tipo Kaldor-Pasinetti. É forçoso notar que Keynes trabalhou com aspectos da redistribuição de renda entre classes selecionadas, já ressaltando as diferentes "propensões a consumir" das classes, desde As consequências econômicas da paz (Keynes, 1919), passando pelo Tract (Keynes, 1923), a mais "clássica" de suas obras nesse aspecto da divisão dos agentes em categorias funcionais, e chegando à Teoria Geral, na qual é evidência inconteste a afirmação de que a "transferência de assalariados para outros fatores [empresários e rentistas] tenderá, provavelmente, a diminuir a propensão a consumir" (Keynes, 1936, p. 262).

(6) Uma tentativa relativamente recente de tratar a propensão média a consumir como variável dependente e incluir uma medida de desigualdade (no caso, o índice de Gini) na lista de variáveis independentes de uma regressão foi feita por Pressman (1997) para dados dos Estados Unidos. Apesar de sua preocupação mais específica com os efeitos redistributivos da política fiscal, os resultados apresentam a direção esperada, isto é, uma relação negativa entre o índice de Gini e a propensão média a consumir. Para uma comparação entre países, o mesmo foi obtido por Khan (1987) também regredindo a propensão média a consumir contra o índice de Gini. 
aumentar a propensão a consumir da comunidade como um todo, assim como diminuir a desigualdade na distribuição pessoal de renda também significa aumentar a propensão a consumir agregada. No contexto da propensão marginal a consumir e do multiplicador, Possas $(1987,89$ n) demonstrou que um multiplicador de inspiração kaleckiana seria dado simplesmente ao desagregarmos uma propensão marginal a consumir para a sociedade como um todo a partir das propensões marginais a consumir das classes selecionadas, sendo aquelas ponderadas pela participação de cada classe na renda agregada.

Enquanto parece mais direta a afirmação de que concentrar a renda entre os que ganham mais, dentro de cada classe, sempre terá um efeito deletério sobre a propensão a consumir correspondente e, com isso, sobre a propensão a consumir como um todo, pode não ser tão claro o efeito de uma transferência de renda, digamos, de um assalariado que está acima do percentil dos que ganham mais - i.e., no grupo do $1 \%$ mais bem remunerado entre os assalariados - para um capitalista ${ }^{7}$ que está abaixo do percentil dos que ganham menos - pertencente ao grupo do $1 \%$ mais mal remunerado entre os capitalistas. A menos que fizéssemos uma hipótese explícita (e arbitrária) também quanto ao montante dos rendimentos (o que define os estratos de renda, não classes funcionais), tal transferência poderia ter o efeito de aumentar a desigualdade na distribuição de renda, reduzindo a propensão marginal a consumir agregada, caso o trabalhador em questão ganhasse menos que o capitalista, ou diminuir a desigualdade, aumentando a propensão marginal a consumir, caso contrário. Por tal motivo, as classes constituem agregações nas quais, assim como para a sociedade como um todo, estamos tomando propensões marginais a consumir para a média (seja da comunidade como um todo ou de uma classe selecionada).

Ao trabalharmos com estratos de renda, o que por vezes é uma opção válida e útil quando se trata de estudos empíricos baseados em pesquisas de orçamentos familiares, não há o risco de incorrermos nesse tipo de dubiedade quanto à redistribuição de renda, perdendo-se uma concepção teórico-analítica potencialmente mais robusta, mas ganhando-se em precisão quanto a afirmações relativas às direções das mudanças distributivas. Experimentos com alguma dose de arbitrariedade na manipulação de diferentes estratos tentando obter efeitos "puros" de uma redistribuição de renda na propensão a consumir podem ser encontrados desde Lubell (1947), por exemplo.

O debate acerca da existência de diferentes propensões marginais a consumir ao longo dos estratos de renda e, consequentemente, de efeitos redistributivos sobre a propensão marginal a consumir agregada persiste até os dias atuais. Com a

(7) Somente para utilizar a distinção habitual entre duas classes, capitalistas e assalariados (ou trabalhadores), como em Kalecki (1942), Kaldor (1956) e Pasinetti (1962), por exemplo. 
declaração de ter ficado "um tanto chocado ao descobrir que a noção de que o consumo agregado é independente da distribuição nunca tenha sido submetida a um teste empírico direto", Blinder (1975, p. 448) inaugura a fase de testes da "moderna" teoria macroeconômica do consumo - aquela decorrente das hipóteses do Ciclo de Vida (Modigliani; Brumberg, 1954) e da Renda Permanente ${ }^{8}$ (Friedman, 1957), concluindo pela "visão que é agora dominante entre macroeconomistas (que a distribuição de renda não importa)" (Blinder, 1975, p. 466). Sugere-se "ou que o consumo é independente da distribuição de renda ou que distribuições com menores medidas de desigualdade levam a um consumo um tanto menor" (Ibid).

Com o propósito de examinar "se as conclusões de Blinder para séries temporais dos Estados Unidos se sustentariam verdadeiras para dados de corte entre os países acerca do padrão de consumo”, Della Valle e Oguchi (1976, p. 1325) encontram, para 10 países da Organização para a Cooperação e Desenvolvimento Econômico (OECD, da sigla em inglês) com medidas comparáveis para a renda disponível, resultados que "pareceriam apoiar a hipótese keynesiana de que uma distribuição de renda mais igualitária resulta em níveis mais elevados de consumo" (Della Valle; Oguchi, 1976, p. 1333). Ainda com o propósito de "perseguir uma sugestão de Blinder (1975), a saber, que 'a única maneira rigorosamente correta de testar para a existência de efeitos distributivos na função de consumo agregado é estimar diretamente propensões marginais a consumir separadas para cada classe de renda",, seguem Borooah e Sharpe (1986, p. 450). Os resultados apresentados por esses autores, para uma divisão pelos quintis da renda para o Reino Unido, apontam que "os quintis diferem um do outro em termos de suas respostas de consumo a mudanças em suas rendas disponíveis" (Borooah; Sharpe, 1986, p. 462), também indicando a plausibilidade do comportamento de longo prazo nos exercícios efetuados: "Assim, os resultados implicam que, em estado estacionário, os quintis mais baixos seriam despoupadores, com a maior parte das poupanças vindo de pessoas no quintil do topo" (Ibid). De volta a análises em cross-country, Khan (1987, p. 1371) encontra resultados "em concordância com a teoria keynesiana convencional de que a equalização da distribuição de renda incrementa o consumo agregado", tanto para países desenvolvidos quanto para países em desenvolvimento, complementando os resultados de Della Valle e Oguchi (1976) que se atinham aos países desenvolvidos.

(8) Naturalmente, a adoção da Hipótese da Renda Permanente implica misturar a riqueza, que poderia constituir, de um ponto de vista keynesiano, parcela autônoma do consumo, com a própria renda corrente que compõe a parcela induzida. Testes que utilizam tal hipótese devem ser vistos com cautela com relação a este ponto. Curiosamente, a Teoria do Ciclo de Vida foi recentemente posta em xeque pelos dados históricos sobre o comportamento da riqueza (e sua desigualdade) apresentados por Piketty (2014, p. 391): "Mas essa teoria [do Ciclo de Vida] do capital e sua evolução nas sociedades avançadas, a qual é perfeitamente plausível a priori, não é capaz de explicar os fatos observados - para dizer o mínimo". 
Bunting (1998, p. 389), de partida, afirma que dados obtidos a partir de pesquisas de orçamento e separados por estratos de renda "nunca foram contraditos, independentemente do lugar ou período de tempo", fornecendo uma explicação para a aparente incoerência entre dados provenientes de séries temporais e de pesquisas de orçamento, apontada por Friedman (1957), que não passa pela separação entre componentes transitórios e permanentes, mas pela relação derivada da distribuição de renda entre os diferentes estratos. "Com efeito, a medida inferencial de Friedman para a renda permanente está realmente medindo a influência da distribuição de renda sobre o consumo" (Bunting: 1998, p. 399), de modo que "a renda transitória, como medida por Friedman, existe porque famílias com parcelas diferentes da renda têm diferentes propensões a gastar" (Ibid). De acordo com Alvarez-Cuadrado e Long (2011, p. 1490), “apesar de seu domínio teórico esmagador, o caso empírico em favor da hipótese da renda permanente é, na melhor das hipóteses, fraco”. Ainda seguindo esses autores, boa parte do trabalho empírico anterior ao advento da hipótese "apresenta forte evidência contra a proporcionalidade das taxas de poupança", sendo que os mais recentes "trabalhos empíricos têm somente confirmado tais achados" (Ibid).

Em um influente artigo, Dynan, Skinner e Zeldes (2004, p. 399, grifos no original) afirmam, no entanto, que "se Friedman e seus colaboradores não lograram uma vitória bem definida nas batalhas empíricas dos anos 1960, eles ganharam a guerra. Modelos a partir de 'agentes representativos' e muitos outros utilizados para avaliação de políticas macroeconômicas ou microeconômicas supõem que as taxas de poupança sejam, no mínimo, invariantes a incrementos proporcionais no total da riqueza humana e física". Considerando que seus achados "não são consistentes com a previsão dos modelos homotéticos padrão de ciclo de vida", Dynan, Skinner e Zeldes (2004, p. 400, grifos no original), sumarizam: "nossos resultados sugerem fortemente que os ricos poupam mais; de modo mais geral, encontramos que as taxas de poupança se elevam ao longo de toda a distribuição. Adicionalmente, apresentamos evidências sugerindo que a propensão marginal a poupar é maior para famílias de renda mais elevada do que para famílias de baixa renda”.

Seja fazendo comparações entre países (e.g. Khan, 1987) ou lidando com séries temporais (e.g. Brown, 2004), não é incomum encontrarmos tentativas de explicar diretamente o nível de consumo agregado a partir de uma equação que inclua alguma medida de desigualdade como variável independente. Do nosso ponto de vista, clamar pela inclusão de mais uma variável explicativa que capte a distribuição de renda em uma função consumo keynesiana típica é incorrer em um erro, antes de tudo, lógico, uma vez que a propensão marginal a consumir deve ser capaz de captar mudanças na distribuição de renda: quão mais desigual é a distribuição de renda, menor é a propensão marginal a consumir e vice-versa, de modo que, do ponto de vista teórico, a inclusão de mais uma variável seria 
redundante. É nessa explicação e a partir de uma estratégia empírica baseada nas parcelas da renda apropriadas pelos diferentes estratos que nos concentraremos no presente estudo.

\section{Descrição preliminar dos dados}

Para a POF de 2002-2003, foram considerados os microdados de 48.568 famílias $^{9}$, que correspondem, levando-se em conta os fatores de expansão específicos fornecidos pelo próprio IBGE, à população de 48.534.638 de famílias no Brasil. Na POF 2008-2009, a amostra foi de 56.091 famílias, representando um universo de 57.816 .604 de famílias.

Foi utilizada a renda total mensal da unidade de consumo como variável de renda, com a finalidade de manter a comparação entre as duas POF possível: apesar de a renda monetária ser fornecida separadamente na POF 2008-2009, sendo potencialmente mais adequada para uma análise empírica do consumo, a mesma categoria não está acessível na pesquisa anterior. Para chegarmos à nossa variável de despesa, adotamos o seguinte procedimento: para cada tipo de registro ${ }^{10}$ quanto à despesa, utilizamos a entrada relativa ao valor da despesa deflacionado, procedemos à anualização (quando esta não estava prontamente disponível) a partir dos seus fatores $^{11}$ também fornecidos na pesquisa e então dividimos o resultado por 12 , obtendo assim a despesa média mensal aos preços da data de referência da pesquisa $^{12}$. Agregando-se, por unidade de consumo, cada lançamento de despesa dos diferentes tipos de registro, finalmente chegamos a uma variável de despesa deflacionada mensal da unidade de consumo.

A renda total captada pela POF, além dos rendimentos da propriedade e do trabalho (que incluem os auferidos pelo empregador e conta-própria), também incluem as transferências advindas de previdência pública ou privada (contabilizando abonos como o décimo terceiro salário), de programas sociais e auxílios diversos, de pensão alimentícia, mesada e doação, de indenizações pagas por seguradoras, etc. Considera-se ainda a variação patrimonial e a renda não monetária, esta última equivalente às aquisições obtidas por doação, troca, produção própria, retirada direta e outras, mais o aluguel imputado ao domicílio cuja condição seja diferente de alugado (IBGE, 2010). Assim, em uma comparação feita por Barros, Cury e Ulyssea (2006), a renda total obtida na POF 2002-2003 estaria 32\%

(9) A família, também denominada unidade de consumo, é a unidade básica de investigação e análise dos orçamentos (IBGE, 2010, p. 22), pois apesar de existirem registros individuais para alguns tipos de despesa, há despesas caracterizadas como de consumo coletivo nas quais a família é a unidade máxima de desagregação possível.

(10) São sete as separações utilizadas na POF 2002-2003 e oito na POF 2008-2009.

(11) Grosso modo, tais fatores de anualização caracterizam a despesa captada como anual (fator 1), trimestral (4), mensal (12) ou semanal (52).

(12) 15 de janeiro de 2009 para a última POF, por exemplo. Os rendimentos já estão expressos para essa data. 
acima da obtida na Pesquisa Nacional por Amostra de Domicílios (PNAD) para 2003 e um pouco acima $(4,4 \%)$ da encontrada no Sistema de Contas Nacionais (SCN) do Brasil para o mesmo ano ${ }^{13}$.

Do lado da despesa total, também constam na POF aumento do ativo e redução do passivo, além das aquisições monetárias típicas de bens e serviços. Outras despesas correntes contêm pagamentos de impostos, contribuições trabalhistas, mesadas, doações e despesas com previdência pública e privada. Ainda há o registro de despesas não monetárias, equivalentes às contrapartes de renda mencionadas, das quais destaca-se, novamente, o aluguel imputado. Considerar de ambos os lados, do consumo e da renda, categorias como as não monetárias leva, naturalmente, à superestimação de uma propensão marginal a consumir a partir da renda, uma vez que aquela se torna unitária, por definição, para tais categorias. Por outro lado, tratar da renda total e não de uma forma de renda disponível após pagamento de impostos e, ao mesmo tempo, incluir parte dos impostos como despesas de consumo, tende a subestimar uma propensão marginal a consumir a partir da renda disponível, que é a relatada em diversos trabalhos. A pertinência da inclusão de categorias de renda e consumo, para os nossos propósitos, não parece carecer de maiores julgamentos, a não ser pela garantia de consistência das definições entre uma pesquisa e outra, portanto, para fins de comparação entre estimativas da propensão marginal a consumir, reconhecendo as limitações impostas pelos dados.

Do ponto de vista das aplicações diretas aos dados das Contas Nacionais, cumpre lembrar que a POF é parte constituinte importante do SCN: de acordo com a metodologia do IBGE (2008, apêndice 3), as famílias são divididas em seis grupos de rendimento nos 26 estados e no Distrito Federal e, assim, a estrutura do consumo obtida via POF é submetida a atualizações anuais a partir dos rendimentos da PNAD, por grupo de renda, para chegar-se ao agregado de consumo final das famílias nas Contas Nacionais. Assim, ainda que grosseiramente, uma parte das mudanças na distribuição de renda acaba por estar refletida no agregado de consumo do SCN. Como utilizamos diretamente os dados de consumo da POF, este estudo não padece de tal viés, apesar de não mensurar diretamente aquela propensão marginal a consumir, seja a partir da renda ou da renda disponível, tipicamente associada aos dados das Contas Nacionais ${ }^{14}$.

Na Tabela 1 estão caracterizadas variáveis de interesse com relação às duas pesquisas de orçamentos familiares, destacando a renda média para ambas as

(13) Deve-se atentar para as observações acerca da noção de renda utilizada no referido artigo (Barros; Cury; Ulyssea, p. 240), de acordo com a qual as diferenças seriam de seis pontos percentuais a menos com relação à PNAD e, na comparação com o SCN, a renda da POF estaria ligeiramente abaixo daquela. Uma descrição detalhada da estrutura da POF pode ser encontrada em Diniz et al. (2007).

(14) Agradecemos a um parecerista anônimo por nos levar a explicitar este ponto. 
pesquisas (em reais de janeiro de 2009), a propensão média a consumir, esta tomada pela divisão entre as médias de consumo e renda, e ainda o índice de Gini para a renda total familiar calculado a partir dos microdados. Comparando com os valores encontrados por Hoffmann (2010a) para a renda familiar per capita (multiplicandoos pelo valor médio de pessoas/família), encontramos valores próximos para a renda familiar média $(\mathrm{R} \$ 2.521,69$ e $\mathrm{R} \$ 2.767,38$, respectivamente, para as duas pesquisas). O índice de Gini calculado por esse autor para a renda familiar per capita, naturalmente, é superior ao aqui apresentado nas duas pesquisas $(0,591$ e 0,561, respectivamente), dada a tendência de famílias de renda mais elevada possuírem um menor número de indivíduos. No entanto, a queda de aproximadamente três pontos percentuais entre 2002-2003 e 2008-2009 foi similarmente observada para ambas as medidas de renda.

Tabela 1

Caracterização básica das POF

\begin{tabular}{l|c|c}
\hline & POF 2002-2003 & POF 2008-2009 \\
\hline Amostra (número de famílias) & 48.568 & 56.091 \\
\hline População (número de famílias) & 48.534 .638 & 57.816 .604 \\
\hline Renda média (R\$ de 2009)* & $2.523,82$ & $2.763,53$ \\
\hline Propensão média a consumir & 0,9746 & 0,8850 \\
\hline Índice de Gini para a renda & 0,5578 & 0,5277 \\
\hline
\end{tabular}

* POF 2002-2003 corrigida para a inflação no período por 1,391437, como em Hoffmann (2010a, p. 649).

Tomando cada um dos centésimos para essa variável de renda, a partir do cálculo dos 99 percentis e a separação da mesma em 100 partes iguais no que tange à população, a média (uma média das médias, pois a renda representativa de cada centésimo é a média das rendas observadas no mesmo) não se alterou substantivamente: se manteve em aproximadamente $\mathrm{R} \$ 2.523,82$ para 2002-2003 e se elevou em 26 centavos, passando para $\mathrm{R} \$ 2.763,79$ considerando a POF 20082009. O índice de Gini obtido a partir da POF 2002-2003 foi 0,5574; para a POF 2008-2008, 0,5274, confirmando o pequeno viés existente ao tomarmos as médias em cada centésimo da distribuição: esse procedimento trata a renda em cada centésimo como igualmente distribuída (todas as famílias pertencentes ao centésimo obtêm o rendimento médio correspondente), de modo que o índice de Gini assim calculado capta somente a desigualdade existente entre os centésimos, e não dentro de cada centésimo da distribuição. Ainda assim, o pequeno viés obtido dá conta do fato de que a desigualdade existente dentro de cada centésimo é relativamente 
pequena (na casa de $0,06 \%$ a $0,07 \%$ do coeficiente) frente à desigualdade existente entre os centésimos.

Tabela 2

Caracterização das POF a partir dos centésimos da renda

\begin{tabular}{l|c|c}
\hline & POF 2002-2003 & POF 2008-2009 \\
\hline Amostra (número de subdivisões) & 100 & 100 \\
\hline Renda média (R\$ de 2009) & $2.523,82$ & $2.763,79$ \\
\hline Índice de Gini para a renda & 0,5574 & 0,5274 \\
\hline
\end{tabular}

\section{Estimativas iniciais para a propensão marginal a consumir}

Apesar dos conhecidos problemas ao lidarmos com estimativas por mínimos quadrados diretamente sobre microdados, em que pese, no nosso caso, a elevada heterogeneidade das famílias com relação a outras variáveis que não o nível de renda familiar (hábitos culturais ou quaisquer outros que influenciem as decisões de consumo, acesso à rede bancária / creditícia, riqueza familiar preexistente, etc.), iniciaremos nossa ilustração estatística por meio de regressões simples entre os níveis de consumo familiar $(C)$ e renda familiar $(Y)$.

Assim, partiremos de estimativas de equações do tipo

$$
C_{i}=\kappa+\alpha Y_{i}+\varepsilon_{i}
$$

onde $\kappa$ representa uma constante, $\alpha$ é a estimativa da propensão marginal a consumir e $\varepsilon$ é o termo de erro. Alternativamente, estimaremos a relação também pelos logaritmos naturais das variáveis, como em uma equação do tipo

$$
\ln C_{i}=\kappa+\beta \ln Y_{i}+\varepsilon_{i}
$$

de modo que a estimativa da propensão marginal a consumir $(\alpha)$ seja dada tomandose as médias de cada variável para a conversão das elasticidades em impactos diretos:

$$
\alpha=\beta \frac{\frac{1}{n} \sum C_{i}}{\frac{1}{n} \sum Y_{i}}
$$

Ou seja, multiplicaremos a propensão média a consumir, obtida conforme acima, pelo coeficiente angular estimado diretamente na regressão por logaritmos.

As estimativas foram realizadas a partir de Mínimos Quadrados Ponderados, sendo que a ponderação para cada família foi realizada pelo fator de expansão 2 (ajustado para estimativas) fornecido na própria pesquisa. Não obstante, deve-se 
destacar que tal ponderação não leva em conta a estrutura do procedimento de amostragem da POF.

Tabela 3

Propensão marginal a consumir agregada a partir dos microdados

\begin{tabular}{l|l|c|c}
\hline & & $\begin{array}{c}\text { POF } \\
2002-2003\end{array}$ & $\begin{array}{c}\text { POF } \\
2008-2009\end{array}$ \\
\hline & Amostra (número de famílias) & 48.568 & 56.091 \\
\hline \multirow{2}{*}{ Regressão de C contra Y } & Índice de Gini para a renda & 0,5578 & 0,5277 \\
\cline { 2 - 4 } & Propensão marginal a consumir $(\alpha)$ & 0,649 & 0,619 \\
\cline { 2 - 4 } & $\mathrm{R}^{2}$ ajustado & 0,549 & 0,453 \\
\hline \multirow{2}{*}{ Regressão de lnC contra $\ln Y$} & Propensão marginal a consumir $(\alpha)$ & 0,765 & 0,722 \\
\cline { 2 - 4 } & $\mathrm{R}^{2}$ ajustado & 0,685 & 0,669 \\
\cline { 2 - 4 } & Propensão média a consumir & 0,975 & 0,885 \\
\hline
\end{tabular}

Esses primeiros resultados, expostos na Tabela 3, demonstram um poder explicativo relativamente baixo, mesmo para o caso das regressões em logaritmos, no qual o $\mathrm{R}^{2}$ ajustado se aproximou da casa dos $70 \%$. Isso não deveria causar surpresa para regressões a partir de microdados, lembrando da citada heterogeneidade: famílias com um mesmo nível de renda podem apresentar padrões de consumo muito diferentes, o que se reflete no grau de ajuste das regressões. Para os níveis, foi observada uma queda da propensão marginal a consumir agregada de 0,649 para 0,619 e, para os logaritmos, uma queda de 0,765 para 0,722 .

É de se esperar, entretanto, que agregações em estratos de renda reduzam essa heterogeneidade juntamente com a variância dos erros de medida na variável explicativa, propiciando um grau de ajuste melhor. Considerando as mesmas equações acima (1 a 3), reestimamos por Mínimos Quadrados Ordinários, a partir da divisão em centésimos da população explicitada anteriormente ${ }^{15}$, as propensões marginais a consumir para as duas POF. Como reportado na Tabela 4, a propensão marginal a consumir para a POF 2002-2003 foi estimada em 0,728 (níveis) e 0,743 (logaritmos), e para a POF 2008-2009 em 0,665 (níveis) e 0,709 (logaritmos). O R ${ }^{2}$ ajustado foi sempre superior a 0,96 , sendo maior para os níveis considerando a POF 2002-2003 e maior para os logaritmos considerando a pesquisa seguinte.

(15) A separação em centésimos foi efetuada a partir dos percentis com os dados ponderados, sendo a renda média resultante em cada centésimo representativa para a população, já levando em conta os fatores de expansão fornecidos pelo IBGE. 
Tabela 4

Propensão marginal a consumir agregada a partir dos centésimos

\begin{tabular}{|c|c|c|c|}
\hline & & $\begin{array}{c}\text { POF } \\
2002-2003\end{array}$ & $\begin{array}{c}\text { POF } \\
2008-2009\end{array}$ \\
\hline & Amostra (número de subdivisões) & 100 & 100 \\
\hline & Índice de Gini para a renda & 0,5574 & 0,5274 \\
\hline \multirow{2}{*}{ Regressão de C contra Y } & Propensão marginal a consumir $(\alpha)$ & 0,728 & 0,665 \\
\hline & $\mathrm{R}^{2}$ ajustado & 0,980 & 0,963 \\
\hline \multirow{3}{*}{ Regressão de $\operatorname{lnC}$ contra $\ln \mathrm{Y}$} & Propensão marginal a consumir $(\alpha)$ & 0,743 & 0,709 \\
\hline & $\mathrm{R}^{2}$ ajustado & 0,966 & 0,973 \\
\hline & Propensão média a consumir & 0,975 & 0,885 \\
\hline
\end{tabular}

Dada a queda da propensão marginal a consumir agregada concomitante à queda do grau de desigualdade, conforme medido pelo índice de Gini, estaria comprometida uma explicação de inspiração keynesiana, na qual claramente a direção teria que ser a inversa? Argumentaremos mais adiante que não, ligando a queda da desigualdade com uma redistribuição das parcelas da renda apropriadas pelos diferentes estratos (que é uma das formas de se calcular o índice de Gini, como veremos), não estando a queda da propensão marginal a consumir ligada a essa redistribuição, como demonstraremos, podendo a mesma estar relacionada a alterações em outros fatores influenciando o consumo, e inclusive ter ocorrido em virtude do aumento da renda média, a qual poderia ser fruto (pelo menos em parte) da própria redistribuição.

Não reunimos até aqui os elementos suficientes, todavia, para chegarmos a essa conclusão, sendo necessário que observemos antes se há alguma evidência de diferença entre as propensões marginais a consumir de diferentes estratos (vale lembrar que até agora estamos falando de uma única propensão marginal a consumir, independentemente do nível de renda). Isso porque, como acreditava Haavelmo (1945, p. 311) já ser de amplo conhecimento, no que tange ao consumo ${ }^{16}$, o "efeito de tal redistribuição, contudo, depende essencialmente de haver ou não uma diferença substancial nas propensões marginais a consumir entre os diversos grupos de renda. Se, por exemplo, a função de propensão marginal a consumir do indivíduo

(16) No contexto desse conhecido artigo, Haavelmo (1945, p. 311) considera que uma redistribuição de renda a partir de uma tributação de mesma monta do gasto público "pode levar a um nível mais elevado de consumo nacional a um dado nível de investimento privado". 
é uma função linear da renda pessoal, a propensão marginal a consumir será constante para todos os níveis de renda e não haverá efeito redistributivo".

Para captar mudanças na inclinação da função consumo, que representam mudanças na própria propensão marginal a consumir, partimos para a tentativa de ajustar poligonais aos nossos dados, conforme descrito na seção seguinte.

\section{Ajuste de poligonais e estimativas de diferentes propensões marginais a consumir}

O reconhecimento de que uma reta de regressão pode não descrever tão adequadamente quanto possível a relação entre duas variáveis, ou seja, o reconhecimento da possibilidade de uma não linearidade nesta relação, comumente leva os pesquisadores a dois conjuntos de soluções: (i) transformações das variáveis em questão para obtenção de linearidade por anamorfose, tais como potenciação, logaritmização, etc.; e/ou (ii) busca por quebras estruturais, de modo que persiste-se com a hipótese de que a relação entre as variáveis é linear, apesar da possibilidade de quebras nesta relação. No contexto deste artigo, com a intenção de investigar-se diferenças entre propensões marginais a consumir para diferentes estratos de renda, a busca por quebras estruturais se coloca como uma opção mais adequada, pois, apesar da exequibilidade de captarmos o comportamento das variáveis por meio de uma relação não linear entre as mesmas, tal opção acabaria por não nos explicitar um ponto específico de mudança nesta relação, além de impossibilitar a mensuração da diferença entre propensões marginais a consumir de forma direta, a partir dos parâmetros estimados.

Dentre as técnicas empregadas para lidar com quebras estruturais, optamos pelo ajuste de uma poligonal em virtude dos ganhos advindos da facilidade de interpretação dos resultados: um coeficiente estimado nos entrega diretamente a diferença entre as inclinações de retas estimadas contiguamente, levando-se em conta um ponto específico de mudança na variável independente. Utilizando os cem diferentes estratos para as variáveis de renda familiar $(Y)$ e consumo familiar $(C)$, ajustamos uma poligonal ${ }^{17}$ para esses dados a partir da seguinte equação:

$$
C_{i}=\kappa+\varphi Y_{i}+\delta Z_{i}\left(Y_{i}-\rho\right)+\varepsilon_{i}
$$

(17) O ajuste de poligonais aos dados das POF, no intuito de estimar as elasticidades do consumo de alimentos, tomando-se, para tal, os logaritmos das variáveis, tem sido feito exitosamente por Hoffmann (2000; 2007; 2010b) a partir de uma divisão em dez classes de renda e levando em conta sempre dois vértices (três segmentos) para a estimativa. 
sendo $Z$ uma variável dicotômica (dummy) que assume os valores $Z_{i}=0$ para $Y_{i} \leq \rho$ e $Z_{i}=1$ para $Y_{i}>\rho$, e $\rho$ o percentil que designa o vértice da poligonal a ser ajustada ${ }^{18}$.

Uma mudança na inclinação representa, assim, uma mudança na própria propensão marginal a consumir. Visualmente (e posteriormente procurando o melhor ajuste a partir do maior $\mathrm{R}^{2}$ ), selecionamos o percentil 92 como o vértice para a nossa poligonal; ou seja, estamos tentando captar uma mudança na inclinação a partir do percentil 92 ( $\rho$ é de R\$6718,02 para a POF 2008-2009 e R\$6329,47 para a POF 2002-2003 em reais de 2009). Assim, estimando-se $\varphi$, temos agora a propensão marginal a consumir até o percentil $92 \mathrm{e}(\varphi+\delta)$ nos fornece a propensão marginal a consumir após o percentil 92.

Para a POF 2002-2003, obtivemos a seguinte representação gráfica, com a linha vertical demarcando o vértice - uma renda de R\$6329,47:

Gráfico 1

Renda X consumo para a POF 2002-2003

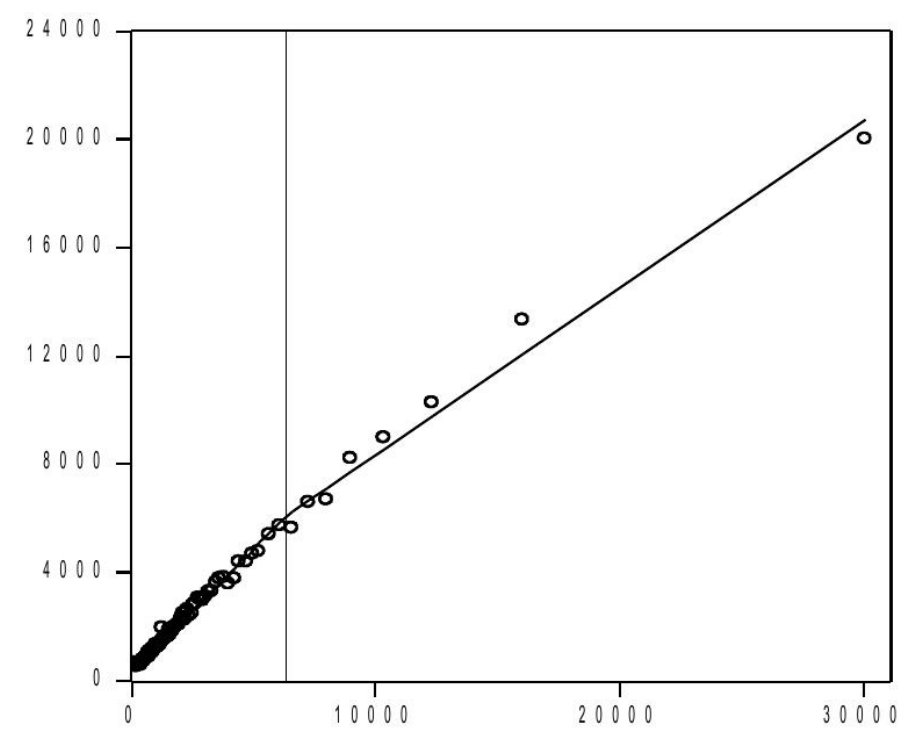

Até o nonagésimo segundo percentil, obtivemos uma propensão marginal a consumir de 0,913; depois do mesmo, um $\delta$ de - 0,295 expressa a queda na propensão marginal a consumir, a qual atinge os 0,618. Assim, estamos considerando que $\alpha_{i}=\varphi \forall i \leq 92$ e $\alpha_{i}=(\varphi+\delta) \forall i>92$. Uma vez que saibamos qual a

(18) Não utilizaremos mais regressões em logaritmos daqui em diante, dado o pequeno ganho de poder explicativo, ou mesmo uma perda como no caso agregado da POF 2002-2003, frente à facilidade de interpretação, inclusive gráfica, propiciada pelas regressões em níveis. 
parcela da renda apropriada pela parcela da população correspondente, expressa por $\Psi$ na Tabela 5, a seguir, obtemos a propensão marginal a consumir agregada por meio de uma média ponderada (por estas parcelas da renda) das propensões marginais a consumir em cada grupo de renda; formalmente, $\alpha=\sum \Psi_{i} \alpha_{i}$. Deve-se destacar que o grau de ajuste, expresso pelo $\mathrm{R}^{2}$ ajustado, se elevou para 0,994 nessa formulação.

Tabela 5

Diferentes propensões para a POF 2002-2003 a partir dos centésimos

\begin{tabular}{l|c|c|c|c}
\hline & $\Psi_{\mathrm{i}}$ & $\alpha_{\mathrm{i}}$ & $\mathrm{R}^{2}$ & $\alpha$ \\
\hline $92 \%$ mais pobres & $60,55 \%$ & 0,913 & & \multirow{2}{*}{0,994} \\
\hline \multirow{2yyn}{*}{$8 \%$ mais ricos } & $39,45 \%$ & 0,618 & & \\
\hline
\end{tabular}

Comparando com resultados obtidos a partir dos microdados, por meio de regressões por Mínimos Quadrados Ponderados, como as rodadas anteriormente para toda a amostra, o mesmo movimento pode ser observado em uma intensidade ainda maior (Tabela 6). A propensão marginal a consumir ligeiramente menor para o grupo dos $92 \%$ mais pobres ${ }^{19}$ (2,4\% abaixo da estimativa anterior) contrasta com uma estimativa substancialmente inferior para o grupo dos $8 \%$ mais ricos (22,2\% abaixo), culminando em uma propensão marginal a consumir agregada 8,5\% abaixo. Há de se notar, todavia, que o grau de ajuste dessas regressões é muito baixo e as amostras (correspondentes a $92 \%$ e $8 \%$ da população, logicamente) têm tamanhos diferentes: enquanto estamos estimando a partir de 45.606 observações para o primeiro grupo, temos somente 2.962 observações no segundo grupo.

Tabela 6

Diferentes propensões para a POF 2002-2003 a partir dos microdados

\begin{tabular}{l|c|c|c|c}
\hline & $\Psi_{\mathrm{i}}$ & $\alpha_{\mathrm{i}}$ & $\mathrm{R}^{2}$ & $\alpha$ \\
\hline $92 \%$ mais pobres & $60,55 \%$ & 0,891 & 0,480 & \\
\hline \multirow{2}{*}{$8 \%$ mais ricos } & $39,45 \%$ & 0,481 & 0,291 & \\
\hline
\end{tabular}

(19) Ao nos referirmos resumidamente aos "mais pobres" ou "mais ricos", estamos tratando dos relativamente mais pobres ou mais ricos, sempre com referência ao grupo oposto. A aproximação "pobres" ou "ricos" para designar níveis de renda menores ou maiores é, como de praxe nessa literatura, também utilizada ao longo do artigo. Vale notar que aqui não há a pretensão de se estabelecer uma medida objetiva para o limite entre os relativamente ricos e os relativamente pobres, como em Hoffmann (2006), mas se trata de uma questão de adequação às poligonais. 
Considerando agora a POF 2008-2009, os resultados são similares. No Gráfico 2 representa-se a poligonal ajustada para um vértice de $\mathrm{R} \$ 6718,02$.

Gráfico 2

Renda X consumo para a POF 2008-2009

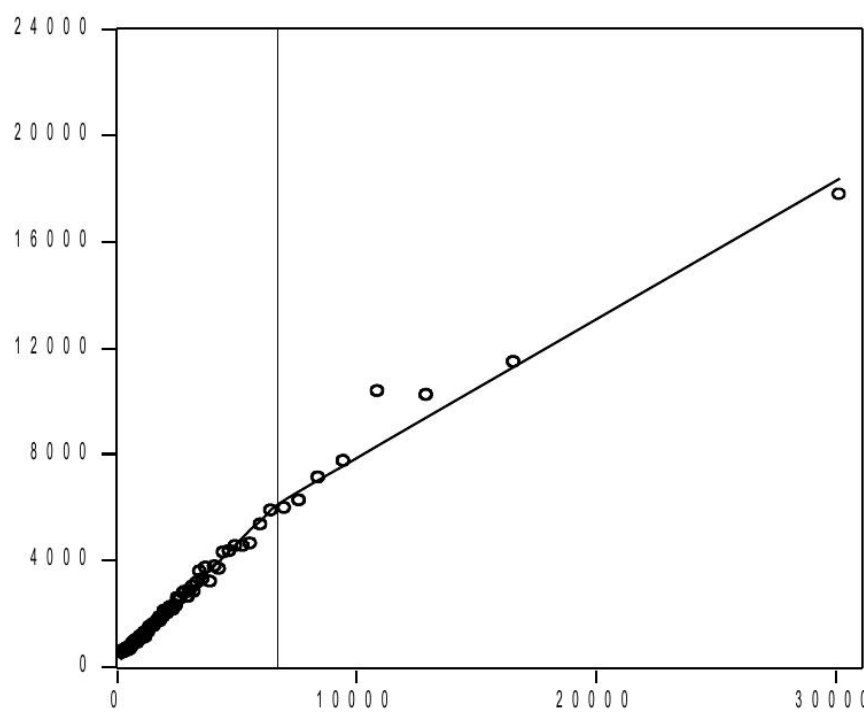

Conforme exposto na Tabela 7, as estimativas a partir dos centésimos apresentam um elevado grau de ajuste e uma diferença ainda mais acentuada da propensão marginal a consumir entre os grupos: enquanto para a POF 2002-2003 a queda da inclinação de 0,913 para 0,618 representava uma variação percentual de $32,3 \%$, a queda de 0,894 para 0,521 constatada para essa POF 2008-2009 representa uma variação percentual de $-41,7 \%$.

Tabela 7

Diferentes propensões para a POF 2008-2009 a partir dos centésimos

\begin{tabular}{l|c|c|c|c}
\hline & $\Psi_{\mathrm{i}}$ & $\alpha_{\mathrm{i}}$ & $\mathrm{R}^{2}$ & $\alpha$ \\
\hline $92 \%$ mais pobres & $62,73 \%$ & 0,894 & \multirow{2}{*}{0,990} & \multirow{2}{*}{0,755} \\
\hline 8\% mais ricos & $37,27 \%$ & 0,521 & & \\
\hline
\end{tabular}

Nas estimativas a partir dos microdados (Tabela 8), a exemplo do explicitado para a POF anterior, temos um baixo grau de ajuste e estimativas menores para os parâmetros: 4,2\% abaixo para o grupo dos $92 \%$ mais pobres e $20,2 \%$ abaixo para o grupo dos $8 \%$ mais ricos, resultando em uma propensão marginal a consumir agregada $8,6 \%$ abaixo da obtida pelo ajuste da poligonal. 
Como o grau de desigualdade afeta a propensão marginal a consumir? Distribuição de renda...

Tabela 8

Diferentes propensões para a POF 2008-2009 a partir dos microdados

\begin{tabular}{l|c|c|c|c}
\hline & $\Psi_{\mathrm{i}}$ & $\alpha_{\mathrm{i}}$ & $\mathrm{R}^{2}$ & $\alpha$ \\
\hline $92 \%$ mais pobres & $62,73 \%$ & 0,853 & 0,398 & \multirow{2}{*}{0,690} \\
\hline $8 \%$ mais ricos & $37,27 \%$ & 0,416 & 0,162 & \\
\hline
\end{tabular}

Assim, comparando somente as estimativas obtidas a partir dos centésimos da renda, teríamos

$$
\begin{gathered}
\alpha_{2002-2003}=0,6055 * 0,913+0,3945 * 0,618=0,797 \mathrm{e} \\
\alpha_{2008-2009}=0,6273 * 0,894+0,3727 * 0,521=0,755 .
\end{gathered}
$$

Tais resultados denotam uma queda na propensão marginal a consumir para a economia como um todo, dada a pequena redução da propensão marginal a consumir entre os $92 \%$ mais pobres e a expressiva redução da propensão marginal a consumir entre os $8 \%$ mais ricos. Todavia, nesse exercício já podemos notar que essa queda se dá a despeito do incremento da proporção de renda apropriada pelos $92 \%$ mais pobres, e não em virtude do mesmo. Em uma manipulação contrafactual, poderíamos nos perguntar o que sucederia caso houvesse essa redistribuição das parcelas da renda e as propensões marginais a consumir para cada grupo se mantivessem as mesmas: a propensão marginal a consumir no agregado se elevaria para 0,803 , visto que teríamos

$$
\alpha=0,6273 * 0,913+0,3727 * 0,618=0,803
$$

Apesar desse tipo de divisão em dois grandes grupos de renda ser suficiente para demonstrar que a propensão marginal a consumir agregada aumenta com uma redistribuição de renda do grupo mais rico para o mais pobre, como o ocorrido no Brasil entre as duas últimas POF, esta não é suficiente para explicitarmos o cálculo simultâneo do índice de Gini a partir dos mesmos dados. Desse modo, faremos um exemplo em seção subsequente utilizando uma divisão a partir dos decis da distribuição, obtendo uma aproximação ainda grosseira para o índice de Gini, e aplicaremos o mesmo método posteriormente para uma divisão pelos percentis, assim obtendo uma boa aproximação para o índice de Gini total. Antes disso, cabe um pequeno desvio para realizarmos a decomposição do índice de Gini em parcelas, ilustrando, de outro ponto de vista, a adequação dessa divisão em dois grandes grupos de renda utilizada para estimarmos a propensão marginal a consumir. 


\section{Uma decomposição do índice de Gini ${ }^{20}$}

Ao termos efetuado, na seção anterior, a divisão da população entre os $92 \%$ mais pobres e os $8 \%$ mais ricos, pelas razões expostas para o ajuste das poligonais, abrimos espaço também para uma decomposição do índice de Gini que explique, dentre os fatores responsáveis pela queda do mesmo de uma pesquisa para outra, o que se deve a uma queda do índice de Gini dentro de cada um desses dois grupos e o que se deve à queda do índice de Gini entre esses grupos. Nessa decomposição, a ideia é captar se as desigualdades de renda se reduziram dentro de cada um desses grandes grupos, ou seja, se a renda se tornou mais igualmente distribuída no grupo dos mais pobres e/ou no grupo dos mais ricos, ou se foi a queda do abismo entre ricos e pobres a responsável pela queda do índice de Gini.

Retornando aos microdados para 2002-2003, já sabíamos que os 92\% mais pobres da população se apropriavam de uma parcela da renda de $60,55 \%$. Aos $8 \%$ mais ricos da população cabia a parcela restante de 39,45\%. Calculando o índice de Gini isoladamente para cada um desses grupos $\left(\mathbf{G}_{\mathbf{h}}\right)$, obtivemos 0,4203 para os mais pobres e 0,2898 para os mais ricos, os quais comporão um coeficiente agregado de 0,5578 .

Consideremos que $\Psi_{h}$ é a proporção da renda apropriada por cada grupo $h$ (os quais representam as parcelas de $92 \%$ e $8 \%$ da população, respectivamente, expressas em $\pi_{h}$ ) e $\Phi_{h}$ é a proporção acumulada da renda até o grupo $h$, sendo, portanto, $\Phi_{h}+\Phi_{h-1}$ a soma da proporção acumulada da renda até o grupo $h$ com a proporção acumulada até o grupo anterior, $h$ - 1 . De acordo com Hoffmann (1998, p. 77), podemos calcular o índice de Gini entre grupos a partir de

$$
\mathbf{G}_{\mathbf{e}}=1-\sum_{h}\left(\Phi_{h}+\Phi_{h-1}\right) \pi_{h}(6)
$$

Ainda conforme Hoffmann (1998: 78), o índice de Gini total pode ser dado por

$$
\mathbf{G}=\mathbf{G}_{\mathbf{e}}+\sum_{h} \pi_{h} \Psi_{h} \mathbf{G}_{\mathbf{h}}
$$

para subdivisões em estratos de renda, onde não haja superposições entre os grupos. Reunimos assim, na Tabela 10, essas informações para os microdados da POF 20022003.

(20) Seguimos Hoffmann (1998) de perto ao longo de toda a seção. 
Como o grau de desigualdade afeta a propensão marginal a consumir? Distribuição de renda...

Tabela 10

Proporções da renda e índice de Gini para a POF 2002-2003

\begin{tabular}{|c|c|c|c|c|c|c|c|}
\hline & $\Psi_{\mathrm{h}}$ & $\Phi_{\mathrm{h}}$ & $\Phi_{\mathrm{h}}+\Phi_{\mathrm{h}-1}$ & $\pi_{\mathrm{h}}$ & $\mathrm{G}_{\mathrm{h}}$ & $\mathrm{G}_{\mathrm{e}}$ & G \\
\hline $92 \%$ mais pobres & 0,6055 & 0,6055 & 0,6055 & 0,92 & 0,4203 & \multirow{2}{*}{0,3145} & \multirow{2}{*}{0,5578} \\
\hline $8 \%$ mais ricos & 0,3945 & 1,0000 & 1,6055 & 0,08 & 0,2898 & & \\
\hline
\end{tabular}

Fazendo o mesmo para a POF 2008-2009, temos, na Tabela 11:

Tabela 11

Proporções da renda e índice de Gini para a POF 2008-2009

\begin{tabular}{l|c|c|c|c|c|c|c}
\hline & $\Psi_{\mathrm{h}}$ & $\Phi_{\mathrm{h}}$ & $\Phi_{\mathrm{h}}+\Phi_{\mathrm{h}-1}$ & $\pi_{\mathrm{h}}$ & $\mathrm{G}_{\mathrm{h}}$ & $\mathrm{G}_{\mathrm{e}}$ & $\mathrm{G}$ \\
\hline 92\% mais pobres & 0,6273 & 0,6273 & 0,6273 & 0,92 & 0,3928 & \multirow{2}{*}{0,2927} & \multirow{2}{*}{0,5277} \\
\cline { 1 - 7 } $8 \%$ mais ricos & 0,3727 & 1,0000 & 1,6273 & 0,08 & 0,2790 & & \\
\hline
\end{tabular}

Podemos, então, perceber que tanto o índice de Gini dentro de cada grupo $h$ quanto o índice de Gini entre os grupos sofreram reduções. Mas podemos inferir ainda mais: para uma queda do índice de Gini total de 0,5578 para 0,5277 (variação de 0,0301, portanto), a queda do índice de Gini entre grupos, $\mathrm{G}_{\mathrm{e}}$, foi de 0,0218 (de 0,3145 para 0,2927), explicando mais de 72\% (para nossos dados menos aproximados, $72,46 \%$ ) da queda global do índice. Ponderando-se pelas participações na população e na renda, a queda do índice de Gini dentro do grupo dos $8 \%$ mais ricos só explica $2,75 \%$ da queda global, enquanto a queda da desigualdade dentro do grupo dos $92 \%$ mais pobres explica os $24,79 \%$ restantes.

Desse modo, podemos afirmar que a queda recente da desigualdade na distribuição de renda familiar, conforme medida pelo índice de Gini, se deveu, em grande monta, a uma queda da desigualdade entre os relativamente mais pobres e os relativamente mais ricos; em nossa divisão, 72,46\% da queda do índice de Gini pode ser explicada por uma queda da desigualdade entre os grupos dos $92 \%$ mais pobres e dos $8 \%$ mais ricos da população.

\section{Um breve exemplo (não inteiramente artificial) de como mudanças no índice de Gini afetam a propensão marginal a consumir}

Nessa seção, formularemos uma ilustração, adiantando alguns resultados empíricos desse artigo (com aproximações bastante grosseiras, condizentes com o espírito da seção, apesar de ainda estarmos utilizando diretamente os dados das POF), na qual demonstraremos como mudanças no índice de Gini, a partir das mudanças da participação relativa na renda de estratos selecionados (os décimos da 
população), afetam a propensão marginal a consumir para a economia como um todo, essa entendida como uma média ponderada (pelas respectivas participações na renda) das propensões marginais a consumir em cada estrato.

Na Tabela 12 estão expostas as principais características dessa aproximação pelos décimos da população, utilizando as propensões marginais a consumir encontradas (Tabelas 5 e 7) até o percentil 92 como representativas para as famílias dos 9 primeiros décimos e as propensões marginais a consumir a partir desse percentil como representativas do último décimo. Nessa aproximação, em que consideramos que cada família pertencente ao décimo ganha a renda média daquele décimo, não estamos atentando para a desigualdade existente dentro de cada décimo. Assim, calculamos o índice de Gini como se só houvesse desigualdade entre os décimos, utilizando a seguinte formulação (Hoffmann, 1998, p. 40):

$$
\mathbf{G}=1-\frac{1}{n} \sum_{i=1}^{n}\left(\Phi_{i}+\Phi_{i-1}\right)
$$

Agora, como antes, consideraremos que $\alpha=\sum \Psi_{i} \alpha_{i}$. Os décimos, de 1 a 10, foram ordenados das rendas menores para as maiores. Podemos perceber, por exemplo, que os $10 \%$ mais pobres da população se apropriavam de $1,2 \%$ da renda em 2002-2003 e passaram a se apropriar de 1,4\% em 2008-2009, enquanto os $10 \%$ mais ricos se apropriavam de 44,1\% em 2002-2003 e passaram a se apropriar de 41,8\% em 2008-2009. Nessa direção, conforme a Tabela 12, o índice de Gini calculado somente a partir da distribuição entre décimos de renda, passa de 0,541 em 2002-2003 para 0,512 em 2008-2009.

Tabela 12

Mudanças nas participações relativas e nas propensões marginais a consumir

\begin{tabular}{rccccc}
\hline \multicolumn{6}{c}{$\mathbf{2 0 0 2 - 2 0 0 3}$} \\
\hline & $\boldsymbol{\Psi}_{\mathbf{i}}$ & $\boldsymbol{\Phi}_{\mathbf{i}}$ & $\boldsymbol{\Phi}_{\mathbf{i}}+\boldsymbol{\Phi}_{\mathbf{i}-\mathbf{1}}$ & $\boldsymbol{\alpha}_{\mathbf{i}}$ & $\boldsymbol{\Psi}_{\mathbf{i}}^{*} \boldsymbol{\alpha}_{\mathbf{i}}$ \\
\hline 1 & 0,012 & 0,012 & 0,012 & 0,913 & 0,011 \\
2 & 0,021 & 0,033 & 0,044 & 0,913 & 0,019 \\
3 & 0,029 & 0,061 & 0,094 & 0,913 & 0,026 \\
4 & 0,037 & 0,099 & 0,160 & 0,913 & 0,034 \\
5 & 0,047 & 0,146 & 0,245 & 0,913 & 0,043 \\
6 & 0,061 & 0,207 & 0,353 & 0,913 & 0,056 \\
7 & 0,079 & 0,286 & 0,492 & 0,913 & 0,072 \\
8 & 0,108 & 0,393 & 0,679 & 0,913 & 0,098 \\
9 & 0,165 & 0,559 & 0,952 & 0,913 & 0,151 \\
10 & 0,441 & 1,000 & 1,559 & 0,618 & 0,273 \\
\hline $\boldsymbol{5}$ & \multicolumn{6}{c}{4,590} \\
\hline \multicolumn{6}{c}{$\boldsymbol{G}=0,541$}
\end{tabular}

\begin{tabular}{llrll}
\hline \multicolumn{5}{c}{$\mathbf{2 0 0 8 - 2 0 0 9}$} \\
\hline$\Psi_{\mathbf{i}}$ & $\boldsymbol{\Phi}_{\mathbf{i}}$ & $\boldsymbol{\Phi}_{\mathbf{i}}+\boldsymbol{\Phi}_{\mathbf{i}-1}$ & $\boldsymbol{\alpha}_{\mathbf{i}}$ & $\boldsymbol{\Psi}_{\mathbf{i}}^{*} \boldsymbol{\alpha}_{\mathbf{i}}$ \\
\hline 0,014 & 0,014 & 0,014 & 0,894 & 0,012 \\
0,024 & 0,038 & 0,051 & 0,894 & 0,022 \\
0,033 & 0,071 & 0,109 & 0,894 & 0,029 \\
0,041 & 0,112 & 0,183 & 0,894 & 0,037 \\
0,051 & 0,163 & 0,275 & 0,894 & 0,046 \\
0,065 & 0,228 & 0,391 & 0,894 & 0,058 \\
0,083 & 0,311 & 0,539 & 0,894 & 0,074 \\
0,110 & 0,420 & 0,731 & 0,894 & 0,098 \\
0,162 & 0,582 & 1,003 & 0,894 & 0,145 \\
0,418 & 1,000 & 1,582 & 0,521 & 0,218 \\
\hline \multicolumn{6}{c}{4,878} \\
\hline
\end{tabular}

Como sabemos os verdadeiros valores para o índice de Gini, calculados a partir dos microdados, podemos perceber quanto está deixando de ser contabilizado (em 
termos dessa medida de desigualdade) pela suposição de que a renda se distribui igualitariamente em cada décimo. No entanto, a queda de 3 pontos percentuais ilustra nosso objetivo sem grandes perdas. Similarmente, a partir da média ponderada das propensões marginais a consumir, uma queda da propensão marginal a consumir agregada na casa dos 4 pontos percentuais ilustra o encontrado anteriormente (Tabelas 5 e 7).

Naturalmente, no caso do cálculo da propensão marginal a consumir, a seguinte simplificação poderia ser feita (já que consideramos a mesma propensão marginal a consumir para os primeiros 9 décimos):

$$
\begin{gathered}
\alpha_{2002-2003}=0,559 * 0,913+0,441 * 0,618=0,783 \mathrm{e} \\
\alpha_{2008-2009}=0,582 * 0,894+0,418 * 0,521=0,738 .
\end{gathered}
$$

Nos falta, mais uma vez, fazer a seguinte pergunta: e se as parcelas da renda fossem redistribuídas do mesmo modo com as propensões marginais a consumir constantes para cada décimo? Na Tabela 13, a seguir, podemos ver (somatório da última coluna à direita) que a propensão marginal a consumir agregada se elevaria para 0,790, apesar (por causa, podemos agora dizer) da queda da desigualdade. Mantidos constantes os demais fatores, que não as parcelas da renda apropriadas pelas diversas parcelas da população, é uma consequência lógica de uma queda no índice de Gini que se eleve a propensão marginal a consumir para a economia como um todo.

Desde que tenhamos (pelo menos duas) diferentes propensões marginais a consumir para os diferentes estratos de renda, no sentido de que quão mais elevado seja o estrato, menor seja a propensão marginal a consumir associada, uma transferência progressiva de renda (que implica redução de qualquer medida de desigualdade que obedeça à condição de Pigou-Dalton) sempre aumentará a propensão marginal a consumir agregada (esta entendida como uma média ponderada das propensões marginais a consumir das famílias), uma vez que a proporção de renda apropriada pelos estratos superiores se reduzirá. A questão é se conseguiremos captar tal alteração, uma vez que a transferência pode ser pequena o bastante para não alterar a propensão marginal a consumir agregada ou pode ocorrer entre estratos (ou famílias) que supostamente ${ }^{21}$ têm a mesma propensão marginal a consumir.

(21) Supostamente porque, deve ficar claro, as propensões marginais a consumir estimadas para grupos de renda (uma vez que não podem ser estimadas para uma única família) captam uma média das propensões marginais a consumir familiares, ou mesmo uma média para os estratos reunidos em um mesmo grupo, não implicando que cada família ou estrato selecionado tenha de fato a mesma propensão marginal a consumir. 
Tabela 13

Contrafactuais: mudanças somente nas participações relativas

\begin{tabular}{rccccc}
\hline \multicolumn{6}{c}{$\mathbf{2 0 0 2 - 2 0 0 3}$} \\
\hline & $\boldsymbol{\Psi}_{\mathbf{i}}$ & $\boldsymbol{\Phi}_{\mathbf{i}}$ & $\boldsymbol{\Phi}_{\mathbf{i}}+\boldsymbol{\Phi}_{\mathbf{i}-\mathbf{1}}$ & $\boldsymbol{\alpha}_{\mathbf{i}}$ & $\boldsymbol{\Psi}_{\mathbf{i}}^{*}{ }^{*} \boldsymbol{\alpha}_{\mathbf{i}}$ \\
\hline 1 & 0,012 & 0,012 & 0,012 & 0,913 & 0,011 \\
2 & 0,021 & 0,033 & 0,044 & 0,913 & 0,019 \\
3 & 0,029 & 0,061 & 0,094 & 0,913 & 0,026 \\
4 & 0,037 & 0,099 & 0,160 & 0,913 & 0,034 \\
5 & 0,047 & 0,146 & 0,245 & 0,913 & 0,043 \\
6 & 0,061 & 0,207 & 0,353 & 0,913 & 0,056 \\
7 & 0,079 & 0,286 & 0,492 & 0,913 & 0,072 \\
8 & 0,108 & 0,393 & 0,679 & 0,913 & 0,098 \\
9 & 0,165 & 0,559 & 0,952 & 0,913 & 0,151 \\
10 & 0,441 & 1,000 & 1,559 & 0,618 & 0,273 \\
\hline $\mathbf{5}$ & \multicolumn{6}{c}{4,590} \\
\hline \multicolumn{7}{c}{$\boldsymbol{G = 0 , 5 4 1}$}
\end{tabular}

\begin{tabular}{llccc}
\hline \multicolumn{5}{c}{$\mathbf{2 0 0 8 - 2 0 0 9}$} \\
\hline $\boldsymbol{\Psi}_{\mathbf{i}}$ & $\boldsymbol{\Phi}_{\mathbf{i}}$ & $\boldsymbol{\Phi}_{\mathbf{i}}+\boldsymbol{\Phi}_{\mathbf{i}-1}$ & $\boldsymbol{\alpha}_{\mathbf{i}}$ & $\boldsymbol{\Psi}_{\mathbf{i}}^{*} \boldsymbol{\alpha}_{\mathbf{i}}$ \\
\hline 0,014 & 0,014 & 0,014 & 0,913 & 0,012 \\
0,024 & 0,038 & 0,051 & 0,913 & 0,022 \\
0,033 & 0,071 & 0,109 & 0,913 & 0,030 \\
0,041 & 0,112 & 0,183 & 0,913 & 0,038 \\
0,051 & 0,163 & 0,275 & 0,913 & 0,047 \\
0,065 & 0,228 & 0,391 & 0,913 & 0,059 \\
0,083 & 0,311 & 0,539 & 0,913 & 0,076 \\
0,110 & 0,420 & 0,731 & 0,913 & 0,100 \\
0,162 & 0,582 & 1,003 & 0,913 & 0,148 \\
0,418 & 1,000 & 1,582 & 0,618 & 0,258 \\
\hline \multicolumn{6}{c}{4,878} \\
\hline
\end{tabular}

Levando adiante tal exercício de construção de uma propensão marginal a consumir agregada contrafactual para a POF 2008-2009, sempre considerando as parcelas da renda efetivamente encontradas para os décimos e fazendo hipóteses acerca da propensão marginal a consumir para cada décimo da população (na Tabela 13 supusemos simplesmente a estabilidade das propensões estimadas para 20022003), poderíamos imaginar uma situação em que a propensão marginal a consumir partisse de um nível próximo da unidade, passasse pelos 0,913 estimados e tivesse uma transição menos brusca para os 0,618 no último décimo. Fizemos este exercício também para estabelecer uma espécie de meio termo entre as duas poligonais estimadas. Graficamente, sem qualquer compromisso estatístico, tentamos fazer com que uma poligonal hipotética, agora com seis segmentos, apresentasse uma transição mais suave entre os mesmos e ainda assim fosse, na média, condizente com as nossas estimativas. A propensão marginal a consumir agregada a partir desta representação seria equivalente à apresentada anteriormente para 2002-2003: 0,783. O Gráfico 3 apresenta nossa poligonal hipotética por meio da linha mais grossa e as poligonais estimadas para 2002-2003 e 2008-2009, respectivamente, pelas linhas cheia e tracejada. 
Gráfico 3

Poligonal hipotética com transições suavizadas

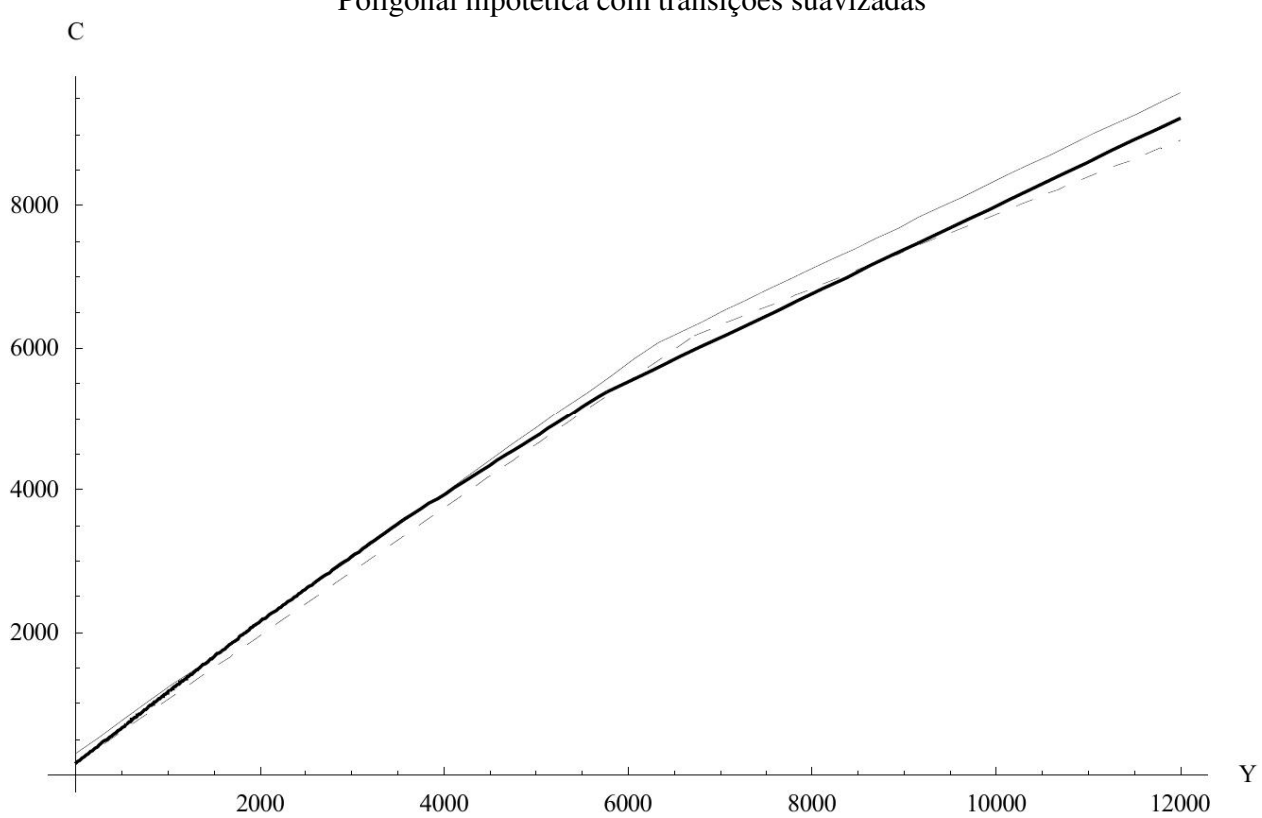

Em números, a poligonal está traduzida em cada propensão marginal a consumir apresentada na Tabela 14: supusemos que a mesma é de 0,998 para os

Tabela 14

Contrafactuais: mudanças nas participações relativas e propensões a consumir hipotéticas

\begin{tabular}{rlcrcc}
\hline \multicolumn{6}{c}{$\mathbf{2 0 0 2 - 2 0 0 3}$} \\
\hline & $\mathbf{\Psi}_{\mathbf{i}}$ & $\boldsymbol{\Phi}_{\mathbf{i}}$ & $\boldsymbol{\Phi}_{\mathbf{i}}+\boldsymbol{\Phi}_{\mathbf{i}-1}$ & $\boldsymbol{\alpha}_{\mathbf{i}}$ & $\boldsymbol{\Psi}_{\mathbf{i}}^{*} \boldsymbol{\alpha}_{\mathbf{i}}$ \\
\hline 1 & 0,012 & 0,012 & 0,012 & 0,998 & 0,012 \\
2 & 0,021 & 0,033 & 0,044 & 0,998 & 0,021 \\
3 & 0,029 & 0,061 & 0,094 & 0,993 & 0,029 \\
4 & 0,037 & 0,099 & 0,160 & 0,993 & 0,037 \\
5 & 0,047 & 0,146 & 0,245 & 0,988 & 0,047 \\
6 & 0,061 & 0,207 & 0,353 & 0,988 & 0,060 \\
7 & 0,079 & 0,286 & 0,492 & 0,913 & 0,072 \\
8 & 0,108 & 0,393 & 0,679 & 0,913 & 0,098 \\
9 & 0,165 & 0,559 & 0,952 & 0,818 & 0,135 \\
10 & 0,441 & 1,000 & 1,559 & 0,618 & 0,273 \\
\hline $\mathbf{5}$ & \multicolumn{6}{c}{4,590} \\
\hline \multicolumn{6}{c}{$\boldsymbol{G = 0 , 5 4 1}$}
\end{tabular}

\begin{tabular}{ccccc}
\hline \multicolumn{5}{c}{$\mathbf{2 0 0 8 - 2 0 0 9}$} \\
\hline $\boldsymbol{\Psi}_{\mathbf{i}}$ & $\boldsymbol{\Phi}_{\mathbf{i}}$ & $\boldsymbol{\Phi}_{\mathbf{i}}+\boldsymbol{\Phi}_{\mathbf{i}-1}$ & $\boldsymbol{\alpha}_{\mathbf{i}}$ & $\boldsymbol{\Psi}_{\mathbf{i}}^{*} \boldsymbol{\alpha}_{\mathbf{i}}$ \\
\hline 0,014 & 0,014 & 0,014 & 0,998 & 0,014 \\
0,024 & 0,038 & 0,051 & 0,998 & 0,024 \\
0,033 & 0,071 & 0,109 & 0,993 & 0,033 \\
0,041 & 0,112 & 0,183 & 0,993 & 0,041 \\
0,051 & 0,163 & 0,275 & 0,988 & 0,051 \\
0,065 & 0,228 & 0,391 & 0,988 & 0,064 \\
0,083 & 0,311 & 0,539 & 0,913 & 0,076 \\
0,110 & 0,420 & 0,731 & 0,913 & 0,100 \\
0,162 & 0,582 & 1,003 & 0,818 & 0,132 \\
0,418 & 1,000 & 1,582 & 0,618 & 0,258 \\
\hline \multicolumn{6}{c}{} \\
\hline \multicolumn{6}{c}{4,878} \\
\hline
\end{tabular}

primeiros dois décimos de renda, passa para 0,993 nos dois décimos seguintes, para 0,988 nos décimos quinto e sexto e para 0,913 (a estimada anteriormente) nos décimos sétimo e oitavo; a partir daí supusemos 0,818 no nono décimo e retornamos aos 0,618 estimados no último décimo. Há uma justificativa para permanecermos 
com valores próximos à unidade por mais tempo e somente a partir dos dois últimos décimos ilustrarmos um declínio maior da propensão marginal a consumir: a propensão média a consumir fica consistentemente abaixo da unidade (i.e., sem mais ultrapassar a mesma em nenhum centésimo subsequente) somente a partir do octogésimo quarto centésimo, para a POF 2002-2003, e do octogésimo primeiro centésimo no caso da POF 2008-2009. Ou seja, somente nos dois últimos décimos da distribuição poderíamos admitir que a renda supera o consumo familiar.

Podemos perceber que, nesse exercício, a propensão marginal a consumir agregada se elevaria em 0,009, em virtude dos mesmos efeitos redistributivos que provocaram a queda do índice de Gini, de 0,783 para 0,792: 0,002 a mais do que o apresentado na Tabela 13.

\section{De volta aos centésimos da população: um exercício mais realista}

No mesmo espírito da seção anterior, utilizando o mesmo instrumental para a obtenção do índice de Gini e da propensão marginal a consumir agregada, podemos aproximar o nosso exercício dos dados reais a partir dos centésimos da população. Como já nos referimos anteriormente e ao contrário das distorções causadas pela suposição de que não há desigualdade de rendimentos em cada décimo da população, supor que a renda está igualitariamente distribuída em cada centésimo (i.e., considerar que cada família pertencente ao centésimo aufere a renda média calculada para tal) nos leva a uma subestimação muito pequena do índice de Gini verdadeiro (o calculado a partir dos microdados) - menos de $0,1 \%$.

Assim, separando a população a partir dos percentis, calculando as parcelas da renda apropriadas por cada centésimo da população e suas respectivas proporções acumuladas da renda, obtivemos, a partir da equação (8) já utilizada anteriormente, o índice de Gini relativo à renda familiar para cada uma das POF: 0,557 para a POF 2002-2003 e 0,527 para a POF 2008-2009. Exibindo alguns centésimos selecionados na Tabela 15 (dada a impraticabilidade de uma descrição completa), podemos notar, entre as pesquisas, o aumento nas proporções da renda apropriadas pelos centésimos mais pobres e o declínio nas proporções da renda apropriadas pelos centésimos mais $\operatorname{ricos}^{22}$.

A partir da ponderação pela participação na renda em cada centésimo, mantidos os valores para as propensões marginais a consumir da poligonal estimada para a POF 2002-2003 (0,913 até o percentil 92 e 0,618 a partir do mesmo), a alteração calculada para a propensão marginal a consumir agregada pelo efeito

(22) Dos centésimos descritos na Tabela 15, pode-se notar esse movimento a partir do octogésimo quinto. De fato, essa inversão (perda de participação relativa) se dá a partir do centésimo 82. Curiosamente, entre os centésimos 81 e 84 podemos localizar os estratos de renda capazes de consumir menos que a renda (ou seja, que possuem uma propensão média a consumir inferior à unidade), como notado acima. 
redistributivo é de 0,006 (ou um aumento de $0,75 \%$ ), passando de 0,797 para 0,803 . Não por acaso, esse é o mesmo resultado apresentado em nossa primeira sugestão de manipulação contrafactual, com os grupos de renda reduzidos a dois, como seria de se esperar desde que tomássemos as proporções da renda corretamente a partir dos dados:

$$
\alpha=0,6273 * 0,913+0,3727 * 0,618=0,803
$$

Tabela 15

Contrafactuais para os centésimos: mudanças somente nas participações relativas

\begin{tabular}{rccccc}
\hline \multicolumn{6}{c}{$\mathbf{2 0 0 2 - 2 0 0 3}$} \\
\hline & $\boldsymbol{\Psi}_{\mathbf{i}}$ & $\boldsymbol{\Phi}_{\mathbf{i}}$ & $\boldsymbol{\Phi}_{\mathbf{i}}+\boldsymbol{\Phi}_{\mathbf{i}-1}$ & $\boldsymbol{\alpha}_{\mathbf{i}}$ & $\boldsymbol{\Psi}_{\mathbf{i}}^{*} \boldsymbol{\alpha}_{\mathbf{i}}$ \\
\hline 1 & 0,000 & 0,000 & 0,000 & 0,913 & 0,000 \\
2 & 0,001 & 0,001 & 0,002 & 0,913 & 0,001 \\
$\vdots$ & $\vdots$ & $\vdots$ & $\vdots$ & $\vdots$ & $\vdots$ \\
5 & 0,001 & 0,004 & 0,007 & 0,913 & 0,001 \\
$\vdots$ & $\vdots$ & $\vdots$ & $\vdots$ & $\vdots$ & $\vdots$ \\
10 & 0,002 & 0,012 & 0,022 & 0,913 & 0,002 \\
$\vdots$ & $\vdots$ & $\vdots$ & $\vdots$ & $\vdots$ & $\vdots$ \\
25 & 0,003 & 0,046 & 0,089 & 0,913 & 0,003 \\
$\vdots$ & $\vdots$ & $\vdots$ & $\vdots$ & $\vdots$ & $\vdots$ \\
50 & 0,005 & 0,146 & 0,287 & 0,913 & 0,005 \\
$\vdots$ & $\vdots$ & $\vdots$ & $\vdots$ & $\vdots$ & $\vdots$ \\
75 & 0,010 & 0,335 & 0,659 & 0,913 & 0,010 \\
$\vdots$ & $\vdots$ & $\vdots$ & $\vdots$ & $\vdots$ & $\vdots$ \\
85 & 0,016 & 0,466 & 0,915 & 0,913 & 0,014 \\
$\vdots$ & $\vdots$ & $\vdots$ & $\vdots$ & $\vdots$ & $\vdots$ \\
90 & 0,021 & 0,559 & 1,097 & 0,913 & 0,019 \\
$\vdots$ & $\vdots$ & $\vdots$ & $\vdots$ & $\vdots$ & $\vdots$ \\
95 & 0,032 & 0,692 & 1,352 & 0,618 & 0,020 \\
$\vdots$ & $\vdots$ & $\vdots$ & $\vdots$ & $\vdots$ & $\vdots$ \\
99 & 0,063 & 0,881 & 1,698 & 0,618 & 0,039 \\
100 & 0,119 & 1,000 & 1,881 & 0,618 & 0,074 \\
\hline $\mathbf{\Sigma}$ & & & 44,255 & & 0,797 \\
\hline & & & $G=0,557$ & & \\
\hline & & & & &
\end{tabular}

\begin{tabular}{|c|c|c|c|c|}
\hline \multicolumn{5}{|c|}{ 2008-2009 } \\
\hline$\Psi_{i}$ & $\Phi_{i}$ & $\Phi_{i}+\Phi_{i-1}$ & $\alpha_{i}$ & $\Psi_{i}^{*} \alpha_{i}$ \\
\hline 0,001 & 0,001 & 0,002 & 0,913 & 0,001 \\
\hline 0,001 & 0,002 & 0,004 & 0,913 & 0,001 \\
\hline : & : & 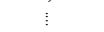 & 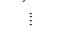 & : \\
\hline 0,001 & 0,005 & 0,009 & 0,913 & 0,001 \\
\hline 1 & : & $\vdots$ & : & ! \\
\hline 0,002 & 0,014 & 0,025 & 0,913 & 0,002 \\
\hline : & : & 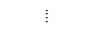 & : & : \\
\hline 0,003 & 0,053 & 0,103 & 0,913 & 0,003 \\
\hline : & : & : & : & : \\
\hline 0,006 & 0,163 & 0,321 & 0,913 & 0,005 \\
\hline 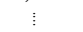 & 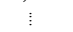 & 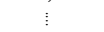 & 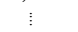 & 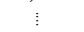 \\
\hline 0,011 & 0,361 & 0,712 & 0,913 & 0,010 \\
\hline : & : & : & : & : \\
\hline 0,015 & 0,492 & 0,968 & 0,913 & 0,014 \\
\hline : & : & 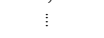 & 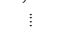 & 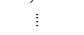 \\
\hline 0,020 & 0,582 & 1,144 & 0,913 & 0,018 \\
\hline 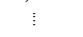 & 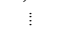 & 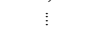 & 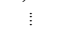 & 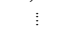 \\
\hline 0,030 & 0,711 & 1,391 & 0,618 & 0,019 \\
\hline 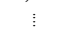 & $:$ & 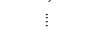 & 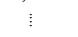 & 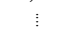 \\
\hline 0,060 & 0,891 & 1,722 & 0,618 & 0,037 \\
\hline 0,109 & 1,000 & 1,891 & 0,618 & 0,067 \\
\hline & & 47,261 & & 0,803 \\
\hline & $G=$ & 0,527 & & \\
\hline
\end{tabular}

Fazendo uma manipulação similar à exposta na Tabela 14 e expressa em nossa poligonal hipotética, novamente partindo da mesma propensão marginal a consumir agregada para 2002-2003, de 0,797, atingiríamos uma propensão marginal a consumir contrafactual para 2008-2009 na casa dos 0,2 pontos percentuais acima, de 0,805 .

\section{Considerações finais}

Ao longo deste artigo procuramos demonstrar que uma queda na desigualdade da distribuição de renda implica um aumento da propensão marginal a consumir agregada. Dentre as diversas estimativas para a propensão marginal a consumir agregada aqui oferecidas para as duas POF, obtivemos um mínimo de 0,619 e um máximo de 0,797. Comparando-as, grosseiramente, com estimativas 
recentes a partir das séries temporais das Contas Nacionais brasileiras, obtidas, portanto, de modo totalmente diverso para o período compreendido entre o terceiro trimestre de 1994 e o primeiro trimestre de 2010, não há uma grande discrepância: essas estariam entre 0,7324 e 0,7718 (Leite, 2012, p. 93-94). Seguindo essa linha, tais estimativas dariam origem a multiplicadores dos gastos autônomos de 1,9298 e 2,0589 , respectivamente.

Considerando uma carga tributária líquida média de 17,49\%, obtida em Dos Santos, Macedo e Silva e Ribeiro (2010), e mantida constante uma propensão marginal a importar, um aumento de $0,75 \%$ na propensão marginal a consumir estimada em 0,7324 (passando para 0,7379 ) geraria um potencial aumento do multiplicador de 1,9298 para 1,9468, o que significaria um aumento potencial do nível de renda de $0,88 \%$ (dados os gastos autônomos à renda no período, naturalmente). Alternativamente, partindo de uma propensão marginal a consumir de 0,7718 , um aumento de $0,75 \%$ resultaria em 0,7776 e na passagem de um multiplicador de 2,0589 para 2,0794 (aumento de aproximadamente 1\%). Em termos nominais, na média para o período compreendido entre o primeiro trimestre de 2003 e o primeiro trimestre de 2009 (tomando os dados das Contas Nacionais), o incremento do PIB gerado por tal aumento da propensão marginal a consumir seria da ordem de 5,1 a 5,8 bilhões de reais.

Partindo dos resultados contrafactuais mais otimistas aqui obtidos, por meio de uma poligonal hipotética gerando um aumento da propensão marginal a consumir agregada de 0,797 para $0,805(1,00 \%)$, teríamos aumentos potenciais do multiplicador (e do nível de renda) entre 1,19\% (propensão marginal a consumir passando de 0,7324 para 0,7398 e multiplicador de 1,9298 para 1,9528 ) e $1,33 \%$ (propensão marginal a consumir passando de 0,7718 para 0,7795 e multiplicador de 2,0589 para 2,0862).

Estimativas apresentadas em Schettini et al. (2012), utilizando uma série trimestral gerada para a renda disponível do setor privado, dão conta de uma elasticidade do consumo com relação à renda disponível em torno de 0,4 e de uma semielasticidade-crédito da ordem de 0,02, destacando que "a importância da renda disponível na determinação do consumo parece cair quando se controla pela importância (crescente, principalmente a partir do primeiro governo Lula) do crédito às famílias" (Schettini et al., 2012, p. 627). De fato, elasticidades-renda muito superiores, próximas à unidade, foram reportadas nos casos em que não se considerou o crédito às famílias (como proporção do PIB) como variável explicativa (Schettini et al., 2012). Em termos teóricos, não haveria razão para a queda nas elasticidades (ou nas propensões marginais a consumir), uma vez que fatores não relacionados à renda, como o crédito, deveriam ser contemplados pela parcela 
autônoma do consumo ${ }^{23}$. Por outro lado, a elevada correlação encontrada, na prática, entre as séries de renda disponível e crédito no período, pode tornar difícil a tarefa de estimar precisamente a relação existente entre consumo e renda disponível. $\mathrm{O}$ crédito poderia, inclusive, ter desempenhado papel mais proeminente que a renda disponível para explicar a trajetória do consumo no período, o que não deveria, teoricamente, alterar a estimativa da elasticidade-renda. $\mathrm{Na}$ prática, contudo, estimativas de parâmetros podem sofrer alterações bruscas quando variáveis independentes altamente correlacionadas são adicionadas ao modelo.

Não obstante a relevância do crédito para explicar a trajetória do consumo, o escopo proposto neste artigo contemplava a mensuração da parcela de consumo induzida pela renda, visando procurar por alterações na propensão marginal a consumir ${ }^{24}$. Ainda assim, todas as afirmações aqui realizadas só puderam ser feitas a partir de manipulações contrafactuais, como se as parcelas da renda fossem avaliadas após uma redistribuição de renda, de fato ocorrida, mantidos constantes os outros fatores não relacionados a essa redistribuição. Desse modo, podemos supor que os potenciais impactos da redistribuição se deram gradativamente, ao longo do tempo, e que o aumento esperado da propensão marginal a consumir agregada foi mais do que compensado por outros fatores. Por outro lado, vale destacar que tais estimativas de impacto sobre a renda pressupõem que os gastos tomados como autônomos à mesma permaneçam constantes, como se a redução da desigualdade de renda fosse incapaz de estimulá-los. Isso porque este artigo tratou, exclusivamente, dos impactos sobre a propensão marginal a consumir, o que não exclui, naturalmente, a possibilidade de outros impactos dinamizadores da renda existirem e se tornarem objeto de estimação. A mudança na estrutura do consumo (i.e., do peso relativo dos diferentes produtos em uma cesta de consumo), particularmente, pode ter efeitos significativos sobre renda real e o emprego, não necessariamente captados por meio de mudanças na propensão marginal a consumir agregada.

As mesmas razões que nos levam a crer que as propensões marginais a consumir são menores para estratos mais elevados de renda podem nos fornecer um indicativo do principal dentre os fatores não relacionados à distribuição atuando no sentido contrário. Como vimos, a propensão marginal a consumir agregada medida pelos dados das POF cai entre uma pesquisa e outra. Acrescentemos mais uma informação (Tabela 16): a renda (real) média se elevou em $9,51 \%$, a renda dos $92 \%$ mais pobres se elevou em $13,45 \%$ e a renda dos $8 \%$ mais ricos se elevou em $3,45 \%$ entre as POF 2002-2003 e 2008-2009.

(23) Deve-se notar que não se trata de menosprezar o papel do crédito no período, mas de enfatizar que o mesmo deveria ser captado por meio da evolução de um componente de consumo independente da renda, não de alterações na propensão marginal a consumir.

(24) Digna de nota é a observação de que a POF possibilita, ainda que parcialmente, uma investigação sobre o crédito a partir da forma de obtenção utilizada para as despesas, se à vista ou com qualquer tipo de parcelamento, diferenciação não contemplada neste artigo. 
Tabela 16

Renda média para as duas POF (R\$ de 2009)

\begin{tabular}{|c|c|c|c|c|c|}
\hline & & \multicolumn{2}{|c|}{ Renda média } & $\alpha_{\mathrm{i}}$ & $\alpha$ \\
\hline \multirow{2}{*}{ POF 2002-2003 } & $92 \%$ mais pobres & 1661,01 & \multirow{2}{*}{2523,82} & 0,913 & \multirow{2}{*}{0,797} \\
\hline & $8 \%$ mais ricos & 12446,14 & & 0,618 & \\
\hline \multirow{2}{*}{ POF 2008-2009 } & $92 \%$ mais pobres & 1884,48 & \multirow{2}{*}{2763,79} & 0,894 & \multirow{2}{*}{0,775} \\
\hline & $8 \%$ mais ricos & 12875,89 & & 0,521 & \\
\hline
\end{tabular}

Esse aumento de renda real possivelmente é o principal responsável pela queda da propensão marginal a consumir conforme medida para as duas pesquisas, uma vez que é de se esperar que maiores níveis de renda estejam relacionados com proporções menores destinadas ao consumo. Keynes (1936, p. 97) expõe os motivos que o levaram a afirmar que, como uma regra, teremos "uma maior proporção da renda sendo poupada quando a renda real se eleva", apesar de ter considerado posteriormente que se tratava de "mera manifestação de opinião, que requer uma investigação estatística maior" do que a realizada até então (Gilboy, 1939, p. 633634). Enquadremos, pois, essa última especulação na mesma categoria.

\section{Referências bibliográficas}

ALVAREZ-CUADRADO, F.; LONG, N. V. The relative income hypothesis. Journal of Economic Dynamics \& Control, 35, p. 1489-1501, 2011.

BARROS, R. P.; HENRIQUES, R.; MENDONÇA, R. Desigualdade e pobreza no Brasil: retrato de uma estabilidade inaceitável. Revista Brasileira de Ciências Sociais, v. 15, n. 42, p. 123-142, 2000.

; CARVALHO, M.; FRANCO, S.; MENDONÇA, R. A queda recente da desigualdade de renda no Brasil. In: BARROS, R. P.; FOGUEL, M. N.; ULYSSEA, G. (Org.) Desigualdade de renda no Brasil: uma análise da queda recente, v.1. Brasília: Ipea, 2006.

; CURY, S.; ULYSSEA, G. A desigualdade de renda no Brasil encontrase subestimada? Uma análise comparativa usando Pnad, POF e Contas Nacionais. In: BARROS, R. P.; FOGUEL, M. N.; ULYSSEA, G. (Org.). Desigualdade de renda no Brasil: uma análise da queda recente, v.1. Brasília: Ipea, 2006.

BLINDER, A. S. Distribution effects and the aggregate consumption function. Journal of Political Economy, v. 83, n. 3, p. 447-475, 1975. 
BOROOAH, V. K.; SHARPE, D. R. Aggregate consumption and the distribution of income in the United Kingdom: an econometric analysis. The Economic Journal, v. 96, n. 382, p. 449-466, 1986.

BROWN, C. Does income distribution matter for effective demand? Evidence from the United States. Review of Political Economy, v. 16, n. 3, p. 291-307, 2004.

BUNTING, D. Distributional basis of aggregate consumption. Journal of Post Keynesian Economics, v. 20, n. 3, p. 389-413, 1998.

CARNEIRO, R. M. Desafios do desenvolvimento brasileiro. In: CARNEIRO, R. M.; MATIJASCIC, M. (Org.). Desafios do desenvolvimento brasileiro. Brasília: Ipea, 2011.

DELlA VALLE, P. A.; OGUCHI, N. Distribution, the aggregate consumption function, and the level of economic development: some cross-country results. Journal of Political Economy, v. 84, n. 6, p. 1325-1334, 1976.

DINIZ, B. P. C.; SILVEIRA, F. G.; BERTASSO, B. F.; MAGALHÃES, L. C. G; SERVO, L. M. S. As pesquisas de orçamentos familiares no Brasil. In: SILVEIRA, E. G. et al. (Org.). Gasto e consumo das famílias brasileiras contemporâneas, v. 2. Brasília: Ipea, 2007.

DOS SANTOS, C. H.; MACEDO E SILVA, A. C.; RIBEIRO, M. B. Uma metodologia de estimação da carga tributária líquida brasileira trimestral no período 1995-2009. Revista de Economia Contemporânea, v. 14, n. 2, p. 209-236, 2010.

DYNAN, K. E.; SKINNER, J.; ZELDES, S. P. Do the rich save more? Journal of Political Economy, v. 112, n. 2, p. 397-444, 2004.

FRIEDMAN, M. A theory of the consumption function. Princeton: Princeton University Press, 1957.

GILBOY, E. W. The propensity to consume. The Quarterly Journal of Economics, v. 53, n. 1, p. 120-140, 1938.

. The propensity to consume: reply. The Quarterly Journal of Economics, v. 53, n. 4, p. 633-638, 1939.

GOMES, F. A. R. Consumo no Brasil: teoria da renda permanente, formação de hábito e restrição à liquidez. Revista Brasileira de Economia, v. 58, n. 3, p. 381402, 2004.

Consumo no Brasil: comportamento otimizador, restrição de crédito ou miopia? Revista Brasileira de Economia, v. 64, n. 3, p. 261-275, 2010.

- Um teste direto da teoria da renda permanente: o caso brasileiro.

Brazilian Business Review, v. 9, n. 4, p. 91-107, 2012. 
GOMES, F. A. R. Gasto do governo e consumo privado: substitutos ou complementares? Revista Brasileira de Economia, v. 67, n. 2, p. 219-234, 2013.

HAAVELMO, T. Multiplier effects of a balanced budget. Econometrica, v. 13, n. 4, p. 311-318, 1945.

HOFFMANN, R. Distribuição de renda: medidas de desigualdade e pobreza. São Paulo: Edusp, 1998.

Elasticidades-renda das despesas e do consumo físico de alimentos no Brasil metropolitano em 1995-1996. Agricultura em São Paulo, v. 47, n. 1, p. 111 $122,2000$.

Queda da desigualdade da distribuição de renda no Brasil, de 1995 a 2005, e delimitação dos relativamente ricos em 2005. In: BARROS, R. P.; FOGUEL, M. N.; ULYSSEA, G. (Org.). Desigualdade de renda no Brasil: uma análise da queda recente, v. 1. Brasília: Ipea, 2006.

- Elasticidades-renda das despesas e do consumo de alimentos no Brasil em 2002-2003. In: SILVEIRA, F. G.; SERVO, L. M. S.; MENEZES, T.; PIOLA, S. F. (Org.). Gasto e consumo das famílias brasileiras contemporâneas, v. 2. Brasília: Ipea, 2007.

Desigualdade da renda e das despesas per capita no Brasil, em 20022003 e 2008-2009, e avaliação do grau de progressividade ou regressividade de parcelas da renda familiar. Economia e Sociedade, v. 19, n. 3, p. 647-661, 2010a

Estimativas das elasticidades-renda de várias categorias de despesa e de consumo, especialmente alimentos, no Brasil, com base na POF de 2008-2009. Revista de Economia Agrícola, v. 57, n. 2, p. 49-62, $2010 \mathrm{~b}$.

; NEY, M. G. A recente queda da desigualdade de renda no Brasil: análise de dados da PNAD, do Censo Demográfico e das Contas Nacionais. Econômica, v. 10, n. 1, p. 7-39, 2008.

INSTITUTO BRASILEIRO DE GEOGRAFIA E ESTATÍSTICA. Sistema de Contas Nacionais Brasil. 2. ed. Rio de Janeiro: IBGE, 2008. (Série Relatórios Metodológicos, 24).

. Pesquisa de Orçamentos Familiares 2008-2009: despesas, rendimentos e condições de vida. Rio de Janeiro: IBGE, 2010.

KALDOR, N. Alternative theories of distribution. The Review of Economic Studies, v. 23, n. 2, p. 83-100, 1956.

KALECKI, M. A theory of profits. The Economic Journal, v. 52, n. 206/207, p. 258$267,1942$. 
KEYNES, J. M. (1919). The economic consequences of the peace. Cambridge: Macmillan, 1971. (The collected writings of John Maynard Keynes, v. II).

(1923). A tract on monetary reform. Cambridge: Macmillan, 1971. (The collected writings of John Maynard Keynes, v. IV).

(1936). The general theory of employment, interest, and money. Cambridge: Macmillan, 1973. (The collected writings of John Maynard Keynes, v. VII).

Mr. Keynes on the distribution of incomes and "propensity to consume": a reply. The Review of Economics and Statistics, v. 21, n. 3, p. 129, 1939.

KHAN, A. H. Aggregate consumption function and income distribution effect: some evidence from developing countries. World Development, v. 15, n. 10/11, p. 13691374, 1987.

LEITE, F. P. Macrodinâmica à keynesiana: uma travessia com consistência entre fluxos e estoques a partir do encadeamento de curtos períodos do multiplicador. Tese (Doutoramento)-Unicamp, Campinas, 2012.

LUBELL, H. Effects of redistribution of income on consumers' expenditure. The American Economic Review, v. 37, n. 1, p. 157-170, 1947.

MODIGLIANI, F.; BRUMBERG, R. Utility analysis and the consumption function: an interpretation of cross-section data. In: KURIHARA, K. (Ed.). Post-Keynesian Economics. New Jersey: Rutgers University Press, 1954.

PASINETTI, L. L. Rate of profit and income distribution in relation to the rate of economic growth. The Review of Economic Studies, v. 29, n. 4, p. 267-279, 1962.

PIKETTY, T. Capital in the Twenty-First Century. The Belknap Press of Harvard University Press, Kindle Edition, 2014.

PRESSMAN, S. Consumption, income distribution and taxation: Keynes' fiscal policy. Journal of Income Distribution, v. 7, n. 1, p. 29-44, 1997.

REIS, E.; ISSLER, J. V; BLANCO, F. CARVALHO, L. M. Renda permanente e poupança precaucional: evidências empíricas para o Brasil no passado recente. Pesquisa e Planejamento Econômico, v. 28, n. 2, p. 233-272, 1998.

SCHETTINI, B. P; SANTOS, C. H.; AMITRANO, C. R.; SQUEFF, G. C.; RIBEIRO, M. B.; GOUVÊA, R. R.; ORAIR, R. O.; MARTINEZ, T. S. Novas evidências empíricas sobre a dinâmica trimestral do consumo agregado das famílias brasileiras no período 1995-2009. Economia e Sociedade, v. 21 (46), p. 607-641, 2012.

STAEHLE, H. Short-period variations in the distribution of incomes. The Review of Economics and Statistics, v. 19, n. 3, p. 133-143, 1937. 
STAEHLE, H. Retail sales and labor income: new considerations on the distribution of incomes and the "propensity to consume" (partly in reply to Mr. Dirks). The Review of Economics and Statistics, v. 20, n. 3, p. 134-141, 1938.

Mr. Keynes on the distribution of incomes and "propensity to consume": a rejoinder. The Review of Economics and Statistics, v. 21, n. 3, p. 129-130, 1939.

STONE, R.; STONE, W. M. The marginal propensity to consume and the multiplier: a statistical investigation. The Review of Economic Studies, v. 6, n. 1, p. 1-24, 1938. 